\title{
Lung and colorectal cancer treatment and outcomes in the Veterans Affairs health care system
}

This article was published in the following Dove Press journal:

Cancer Management and Research

14 January 2015

Number of times this article has been viewed

\author{
Leah L Zullig',2 \\ Christina D Williams s $^{3,4}$ \\ Alice G Fortune-Britt ${ }^{1,5}$ \\ 'Center for Health Services Research \\ and Development in Primary Care, \\ Durham Veterans Affairs Medical \\ Center, ${ }^{2}$ Department of Medicine, \\ Division of General Internal \\ Medicine, Duke University Medical \\ Center, ${ }^{3}$ Medical Service, Division \\ of Hematology-Oncology, Durham \\ Veterans Affairs Medical Center, \\ ${ }^{4}$ Department of Medicine, Division of \\ Medical Oncology, Duke University \\ Medical Center, Durham, ${ }^{5}$ Department \\ of Health Policy and Management, \\ University of North Carolina, \\ Chapel Hill, NC, USA
}

\begin{abstract}
Lung cancer (LC) and colorectal cancer (CRC) are the second- and third-most commonly diagnosed cancers in the Veterans Affairs (VA) health care system. While many studies have evaluated the treatment quality and outcomes of various aspects of VA LC and CRC care, there are no known reviews synthesizing this information across studies. The purpose of this literature review was to describe LC and CRC treatment (ie, surgical and nonsurgical) and outcomes (eg, mortality, psychosocial, and other) in the VA health care system as reported in the existing peer-reviewed scientific literature. We identified potential articles through a search of published literature using the PubMed electronic database. Our search strategy identified articles containing Medical Subject Headings terms and keywords addressing veterans or veterans' health and LC and/or CRC. We limited articles to those published in the previous 11 years (January 1, 2003 through December 31, 2013). A total of 230 articles were retrieved through the search. After applying the selection criteria, we included 74 studies (34 LC, 47 CRC, and seven both LC and CRC). VA provides a full array of treatments, often with better outcomes than other health care systems. More work is needed to assess patient-reported outcomes.
\end{abstract}

Keywords: colorectal neoplasms, health services research, lung neoplasms, outcome assessment (health care), review, United States Department of Veterans Affairs

\section{Introduction}

Lung cancer (LC) and colorectal cancer (CRC) are the second- and third-most commonly diagnosed cancers among men and women in the US, together accounting for approximately $20 \%$ of all new cancer cases annually. ${ }^{1}$ In 2014, an estimated $224,210 \mathrm{LC}$ and 136,830 CRC cases along with 159,260 LC and 50,310 CRC deaths will occur. ${ }^{1}$ Age and cigarette smoking are the predominant risk factors for LC, although other environmental and occupational exposures, such as asbestos and radon, may also increase lung cancer risk. ${ }^{2}$ Well-known risk factors for CRC include age, obesity, physical inactivity, alcohol consumption, and unfavorable dietary habits, such as increased red and processed meat consumption and low fruit and vegetable intake., ${ }^{3,4}$ Cancer care is complex, and a number of organizations have set forth guidelines for the management of LC and CRC care.

Patients with cancer receiving care in the Veterans Affairs (VA) health care system represent about $3 \%$ of all cancer patients in the US. ${ }^{5}$ A national-level study using the VA Central Cancer Registry to assess cancer incidence among veterans noted that lung and bronchus cancers account for nearly $20 \%$ of all cancers among veterans, and CRC accounts for $9 \% .{ }^{5}$ While comparisons have been made between VA and non-VA care for both $\mathrm{LC}$ and $\mathrm{CRC},{ }^{6-10}$ the VA population is unique in that most patients have
Correspondence: Leah L Zullig 4 II West Chapel Hill Street Suite 600, Durham, NC 2770I, USA

$\mathrm{Tel}+\mathrm{I} 91928604$ I I ext 7586

Fax +19194165839

Email leah.zullig@va.gov 
poor health and lower education and income. ${ }^{11-14}$ Given the aging population, increase in military personnel exiting active duty, and potential increase in veterans seeking health care in VA, the cancer burden in VA will increase. Therefore, it is important to assess current treatment practices and impact on outcomes in the VA cancer population to identify areas for improvement.

The objective of this review was to describe LC and CRC treatment (ie, surgical and nonsurgical) and outcomes (eg, mortality, psychosocial, and other) in the VA health care system as reported in the existing peer-reviewed scientific literature. To our knowledge, this is the first comprehensive review of cancer treatment and outcomes in patients receiving care in the VA health care system.

\section{Materials and methods}

We identified potential articles through a search of published literature using the PubMed electronic database. Our search strategy identified articles containing Medical Subject Headings and keywords in the title and abstract addressing veterans or veterans' health and LC and/or CRC (Table 1). We limited articles to those published in English in the previous 11 years (January 1, 2003 through December 31, 2013).

This initial search yielded 230 unique articles. We then screened abstracts and full articles for eligibility. The following exclusion criteria were applied: non-US veterans (or inability to distinguish between veterans and nonveterans in the study population), noncancer or other cancers,

Table I Search strategy for Veterans Affairs (VA) lung and colorectal cancer treatment and outcomes

\begin{tabular}{|c|c|}
\hline Database & PubMed \\
\hline Time frame & $\begin{array}{l}\text { Articles published January I, } 2003 \text { through December 3I, } \\
2013\end{array}$ \\
\hline $\begin{array}{l}\text { Search } \\
\text { terms }\end{array}$ & $\begin{array}{l}\text { (((““United States Department of Veterans Affairs” } \\
\text { [MeSH] OR “hospitals, veterans” [MeSH] OR “veterans } \\
\text { health” [MeSH] OR “veterans” [MeSH]) AND (“lung } \\
\text { neoplasms” [MeSH] OR “colorectal neoplasms” [MeSH]) } \\
\text { AND (“2003/0I/0I” [PDAT]: "20I3/I2/3I” [PDAT]))) } \\
\text { OR ((((lung cancer [title/abstract]) OR colorectal cancer } \\
\text { [title/abstract]) OR colon cancer [title/abstract]) OR } \\
\text { rectal cancer [title/abstract])) AND ((veteran [title/ } \\
\text { abstract]) OR VA [title/abstract]) }\end{array}$ \\
\hline $\begin{array}{l}\text { Exclusion } \\
\text { criteria }\end{array}$ & $\begin{array}{l}\text { - Non-English language } \\
\text { - Non-US veterans (or inability to distinguish between } \\
\text { treatment/outcomes of veterans and nonveterans } \\
\text { within the article) } \\
\text { - Noncancer or other cancers } \\
\text { - Nonepidemiological or not original research (eg, } \\
\text { commentaries, feasibility studies) } \\
\text { - Described only risk or barriers to care }\end{array}$ \\
\hline
\end{tabular}

Abbreviations: MeSH, Medical Subject Headings; PDAT, publication date. nonepidemiological or not original research (eg, commentaries, feasibility studies), or description of only risk or barriers to care. We included retrospective analyses, cross-sectional, and prospective studies. A full description of this process is outlined in Figure 1.

\section{Results}

A summary of published studies describing LC and CRC among veterans is presented in Tables 2 and 3, respectively.

\section{Lung cancer}

\section{Surgical treatment}

There were eight articles that addressed receipt of surgery and/or predictors of surgical treatment. Dransfield et al reported that among 156 patients with non-small-cell LC (NSCLC), 31 underwent resection, and a majority of these (61\%) were diagnosed at the time of surgery. ${ }^{15}$ In a study including all patients diagnosed with LC in 2007, the surgery rate was $69 \%(909$ of 1,314$)$ among those with stages I and II NSCLC ${ }^{16}$ This was similar to the $65.4 \%$ of stage I and II NSCLC patients who received surgery in the full cohort in the VA-wide study by Landrum et al of patients diagnosed in 2003-2004. ${ }^{17}$ In another national-level cohort of VA patients, $51 \%$ of patients aged 65 years and older with localized LC had surgery. ${ }^{18}$ Zeber et al conducted a national-level study of elderly veterans comparing receipt of treatment for LC patients aged 70-84 years $(n=19,010)$ to those 85 years and older ( $\mathrm{n}=1,347)$, and found that $2.7 \%$ of all $\mathrm{LC}$ patients aged 70-84 years had surgery compared to $0.5 \%$ of those over 85 years. ${ }^{19}$ When surgical resection patterns among veterans and nonveterans were compared, it was noted that resection rates were similar for older veterans $(70.2 \%)$ and nonveterans $(71.2 \%)$ with early stage disease, but among younger patients the resection rate was lower in veterans $(83.3 \%)$ compared to nonveterans $(91.5 \%){ }^{20}$ In two small studies, each done at a single VA facility, one study observed that $20 \%$ of stage I-IIIA patients got surgery ${ }_{15}^{15}$ and the other reported a $28 \%$ surgery rate among all stages. ${ }^{21}$

Four of these seven studies identified factors associated with receipt of surgery. In a single-institution study, the authors noted that surgery patients were less likely to have chronic obstructive pulmonary disease (COPD) and typically had better pulmonary function, while those who did not have surgery most often had advanced disease (75\%), poor pulmonary function $(5 \%)$, or refused $(4 \%) .{ }^{15}$ National-level studies by Williams et al and Wang et al both reported that lower treatment rates were associated with increasing age, 


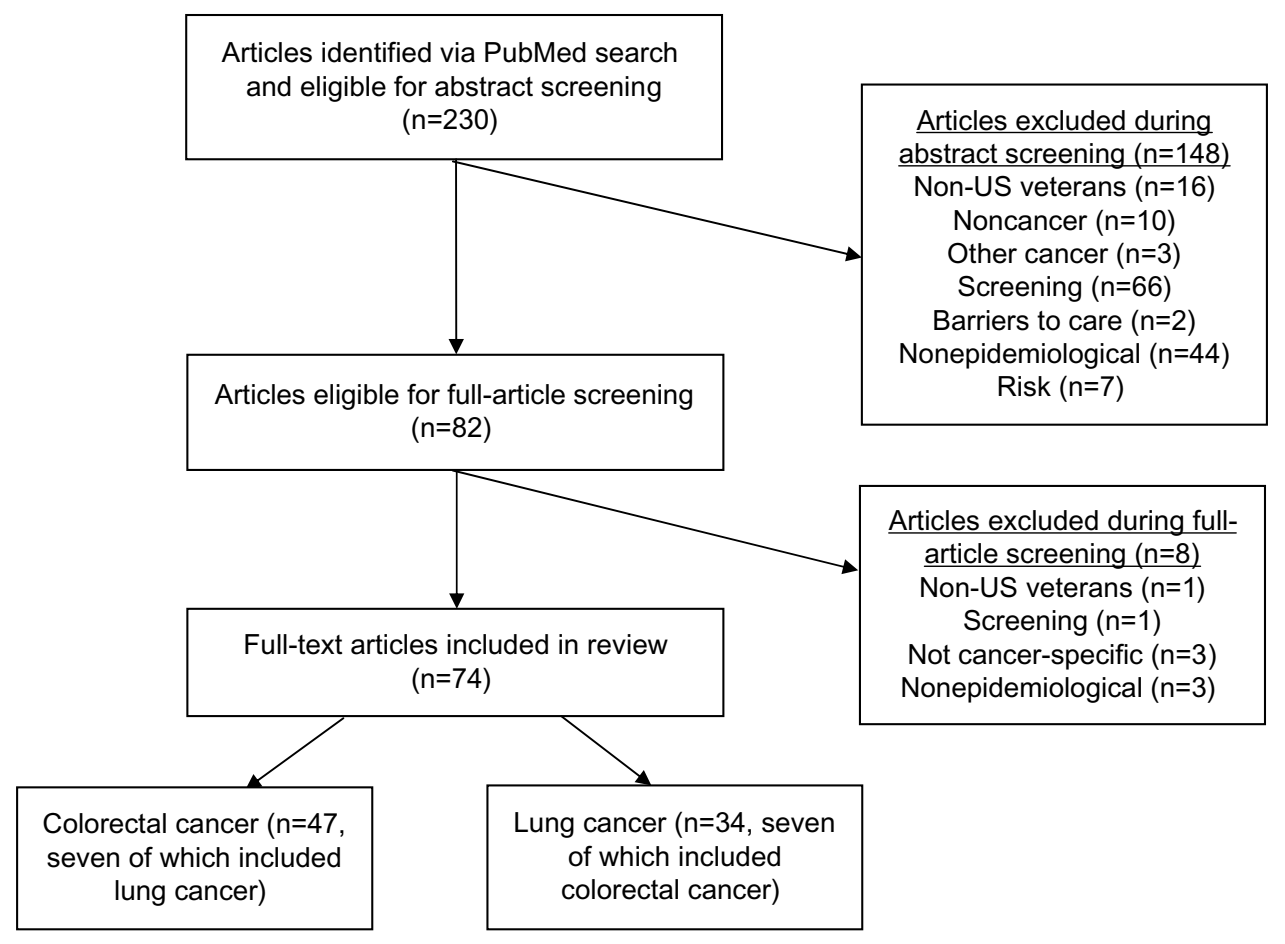

Figure I Schema for article-selection process.

black race, severe comorbidity, and respiratory disease. ${ }^{16,18}$ For example, resection rates for local disease among patients $65-74$ years old were $59.8 \%$ and $43.1 \%$ for those aged $75-84$ years and $18.5 \%$ for those over age 85 years. ${ }^{18}$ Williams et al reported that blacks were significantly less likely to receive surgery compared to whites (odds ratio $0.63,95 \%$ confidence interval [CI] 0.48-0.83), and receipt of surgery also varied within the categories of marital status, histology, smoking status, and region. ${ }^{16}$ In an article by Landrum et al that identified reasons for not receiving guideline-recommended treatment, predominant reasons for nonreceipt of curative surgery for stage I/II LC included poor health $(61 \%)$ and refusal $(26 \%){ }^{17}$

\section{Nonsurgical treatment}

We identified two studies that evaluated receipt of nonsurgical treatment, both of which were done among elderly veterans. In an article by Wang et al, the authors used a cohort of patients aged 65 years and older to assess receipt of first-line recommended treatment according to National Comprehensive Cancer Network guidelines. ${ }^{18}$ The recommended treatment for regional NSCLC is surgery plus chemotherapy, with or without radiation if the patient is eligible for surgery, or chemotherapy plus radiation if the patient is not a surgical candidate. Chemotherapy is the standard of care for patients with metastatic disease. Based on these guidelines, this study found that $35 \%$ of patients with regional disease and $27 \%$ with metastatic disease received appropriate treatment. Treatment rates varied a great deal according to age. For patients with regional disease, rates ranged from $44.7 \%$ for those aged $65-74$ years to $14.0 \%$ for those over 85 years. Corresponding rates for metastatic disease were $34.3 \%$ and $9.3 \%$. Zeber et al examined treatment modalities using a cross-sectional study of patients aged 70 years and older. ${ }^{19}$ Among LC patients aged $70-84$ years, $4.8 \%$ received radiation and $9.0 \%$ received chemotherapy. For patients aged 85 years and older, 3.3\% got radiation, while $2.9 \%$ got chemotherapy.

\section{Timeliness of care}

When the timeliness of LC care is considered, it is important to note that although several studies have evaluated "guideline-recommended" timeliness, these guidelines are not based on scientific evidence that shorter time periods produce better outcomes. In the period for the literature search for this review, there were seven studies published on the timeliness of LC care among veterans. Three nationallevel studies examined the timeliness of care within VA. One of these studies found that the median time between the first radiography and treatment was 71 days, ${ }^{22}$ while another study reported the median times between suspicion and diagnosis as 33 days and suspicion to treatment as 63 days. ${ }^{23}$ A national-level study among late-stage NSCLC 


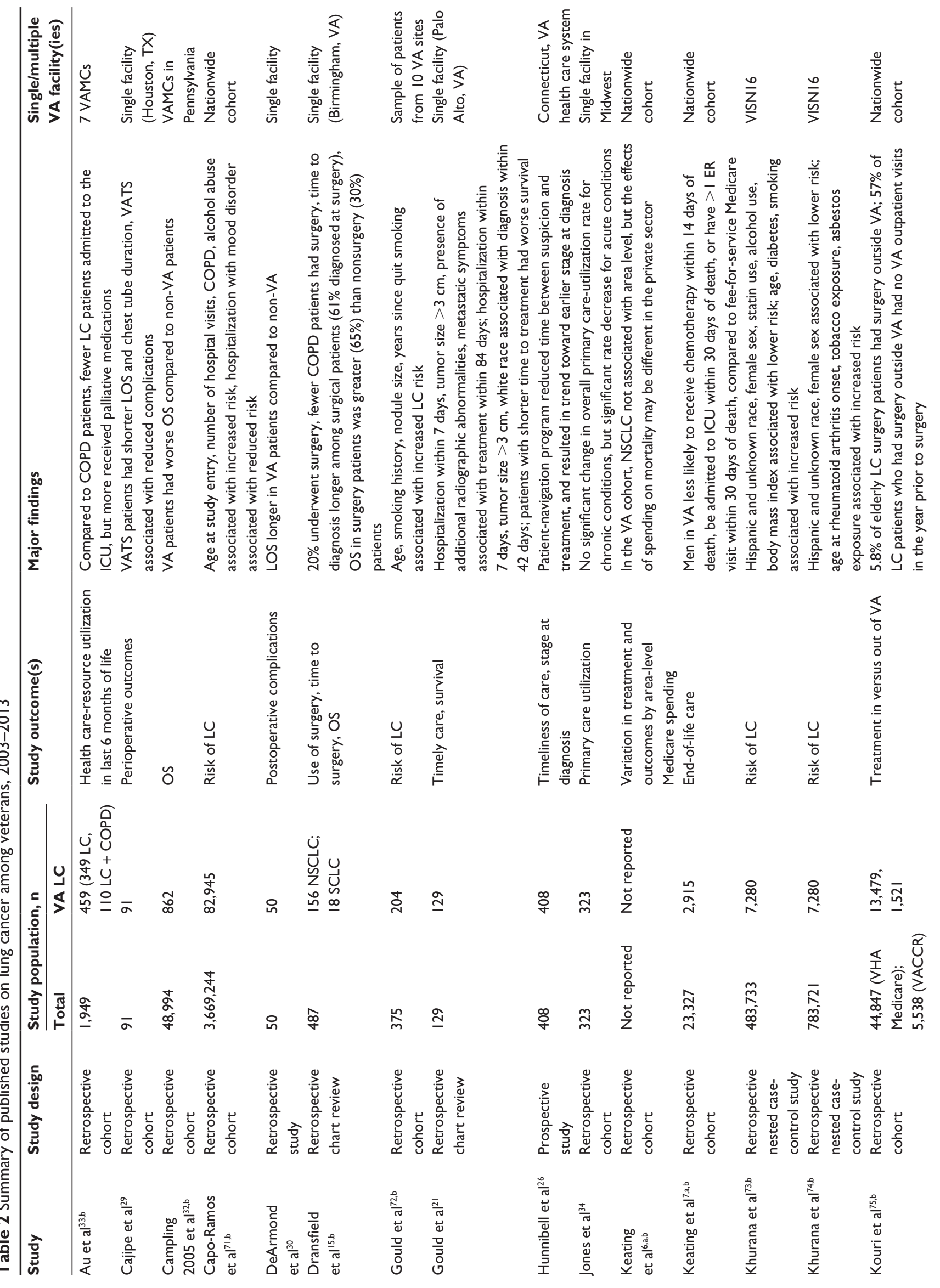




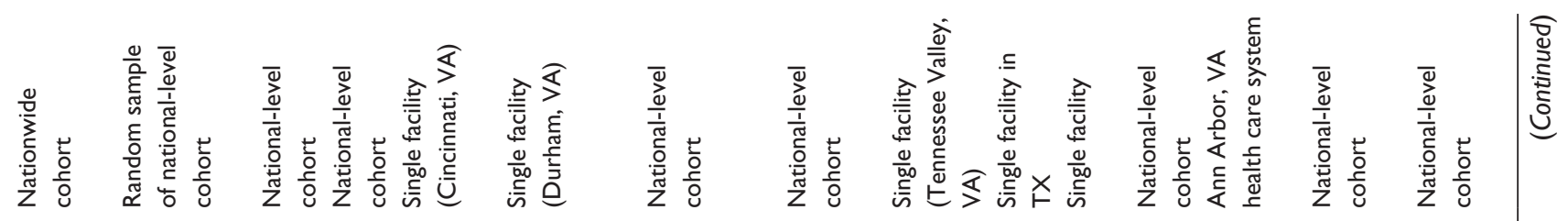

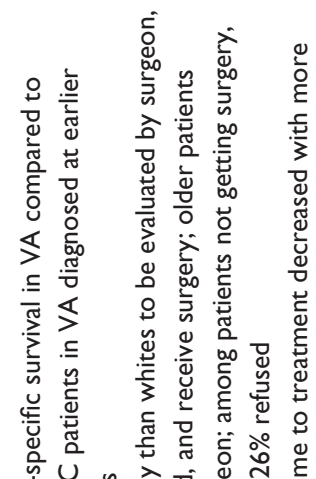

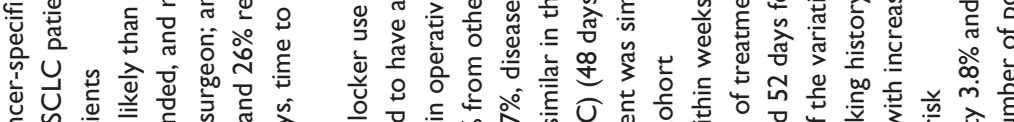

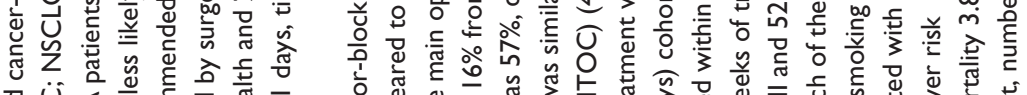

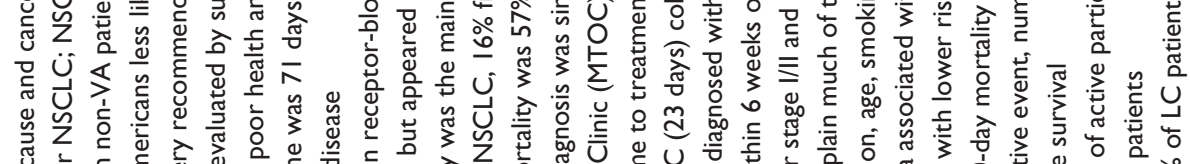

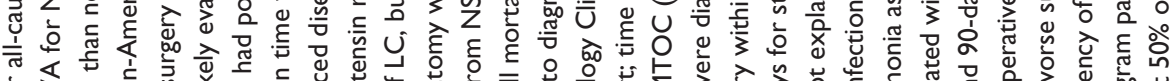

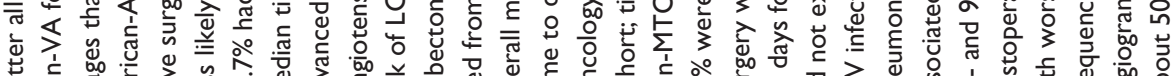

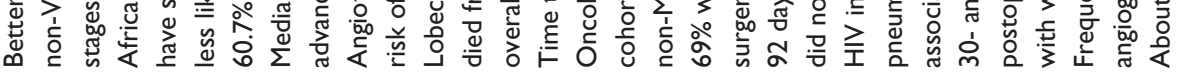
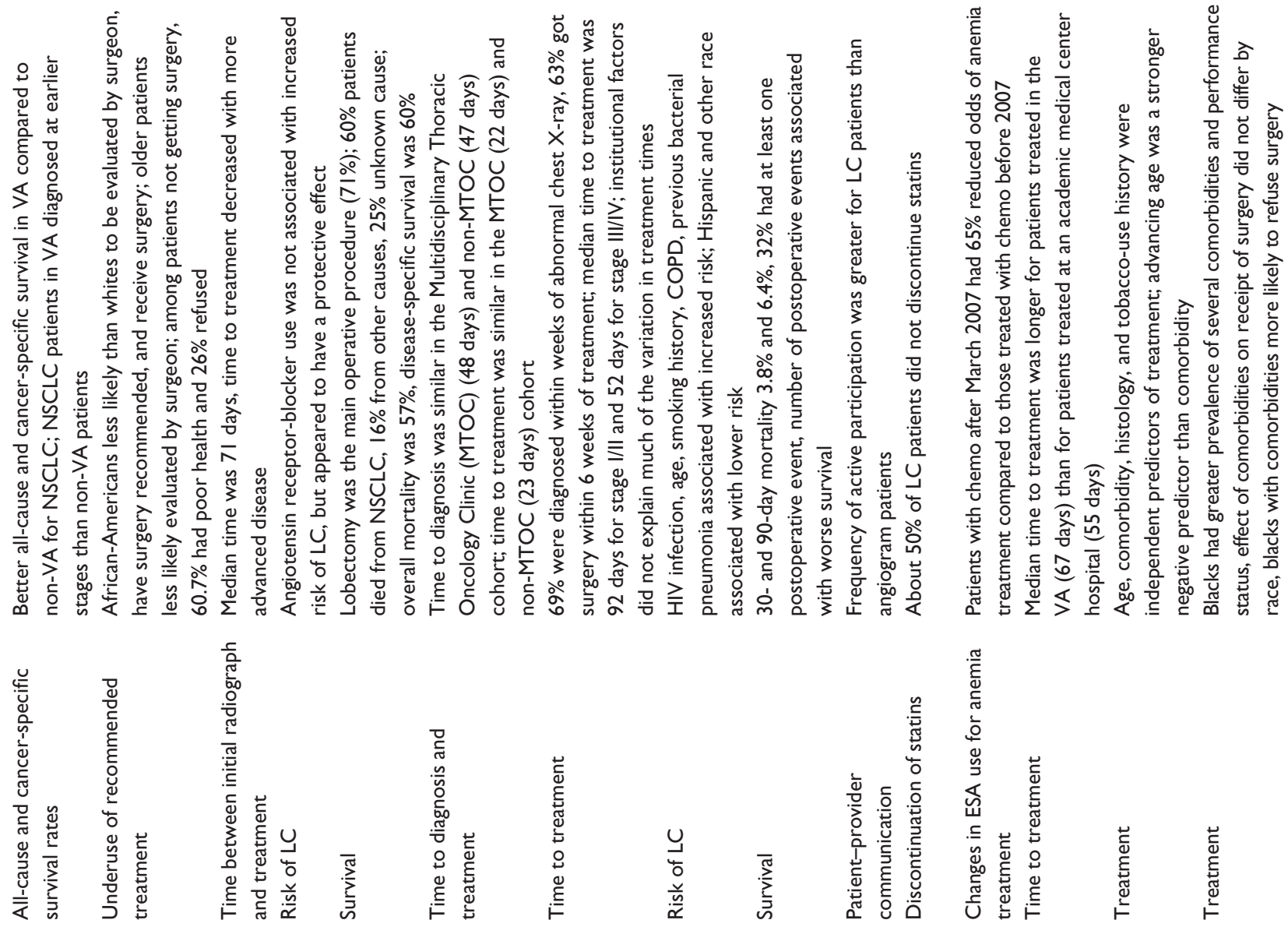

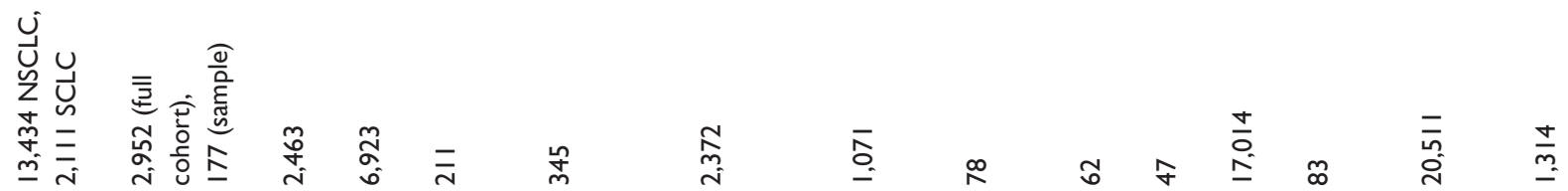

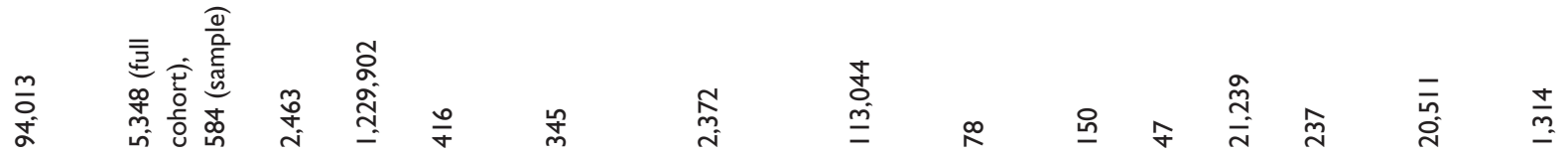

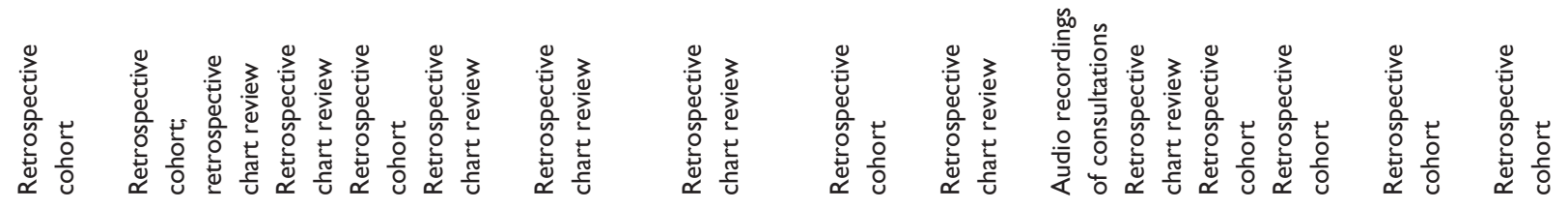

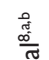

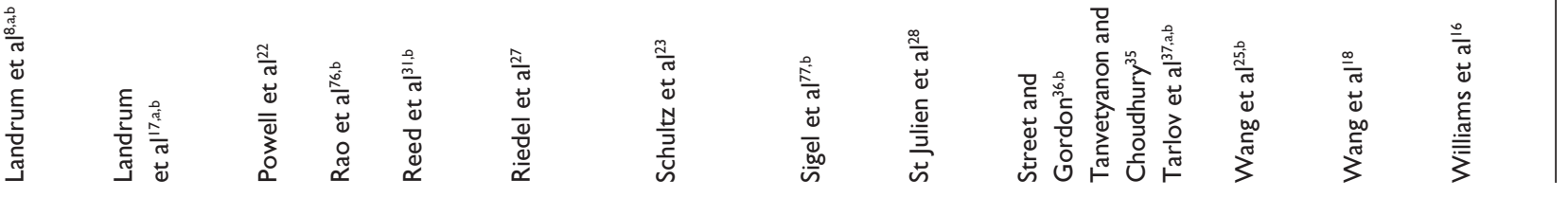




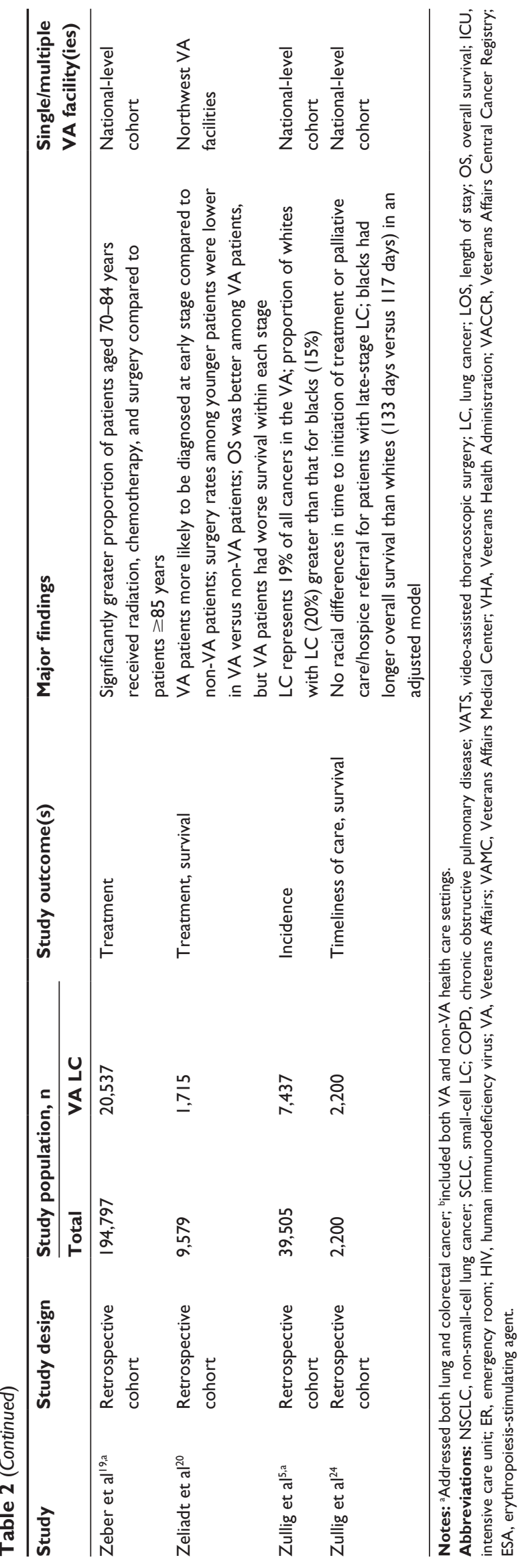

patients reported 66 days as the mean time from diagnosis to initiation of treatment. ${ }^{24}$ The studies including all LC stages; both reported shorter time to treatment for advanced stages, ${ }^{22,23}$ one of which found that patients receiving radiation or chemotherapy were treated sooner than those undergoing surgery. ${ }^{22}$ Another noted a $69 \%$ adherence rate to the recommended guideline for receipt of diagnosis within 8 weeks of suspicion. ${ }^{23}$

Wang et al compared time to treatment in a single VA compared to a nearby academic medical center, and found that the median time to treatment was longer for patients treated in VA (67 days) than for patients treated at a hospital (55 days). ${ }^{25}$ The other studies examining the timeliness of care were each conducted at a single VA facility. One facility evaluated the impact of having a cancer care coordinator to improve timeliness of care for patients potentially having $\mathrm{LC},{ }^{26}$ and found that the time between suspicion and treatment was reduced to 55 days, compared to 136 days in previous years. On the contrary, incorporation of a multidisciplinary thoracic oncology clinic at another facility did not appear to improve times to diagnosis and treatment. ${ }^{27}$ The time intervals between initial presentation to diagnosis before and after initiation of the multidisciplinary thoracic oncology clinic were 47 days and 48 days, respectively. ${ }^{27}$ Corresponding times between diagnosis and treatment were 22 and 23 days, respectively. ${ }^{27}$ Another single-facility study documented 84 days between suspicion and treatment (range 38-153 days). ${ }^{21}$ This study further determined that predictors of timely treatment included hospitalization within 7 days of the initial cancer suspicion, a tumor size greater than $3.0 \mathrm{~cm}$, other abnormalities on chest radiograph, and presence of metastatic symptoms, and determinants of timely diagnosis included hospitalization within 7 days, tumor size greater than $3.0 \mathrm{~cm}$, and white race.

\section{Postoperative outcomes}

In a retrospective review of 78 patients undergoing surgery for pathologic stage I LC, approximately a third of patients had at least one postoperative event, with the most common being pneumonia (17\%) and reintubation (13\%). ${ }^{28}$ Another small study comparing video-assisted thoracoscopic (VATS) lobectomy ( $\mathrm{n}=46)$ with open lobectomy $(\mathrm{n}=45)$ found that VATS patients had a shorter length of stay and shorter chesttube duration and that VATS was associated with a lower risk of complications. ${ }^{29}$ DeArmond et al also examined patients undergoing VATS lobectomy, and compared outcomes of VA and non-VA patients. ${ }^{30}$ They noted that average length of stay was significantly longer in VA versus non-VA patients (6.4 days versus 3.6 days, $P=0.022$ ). 


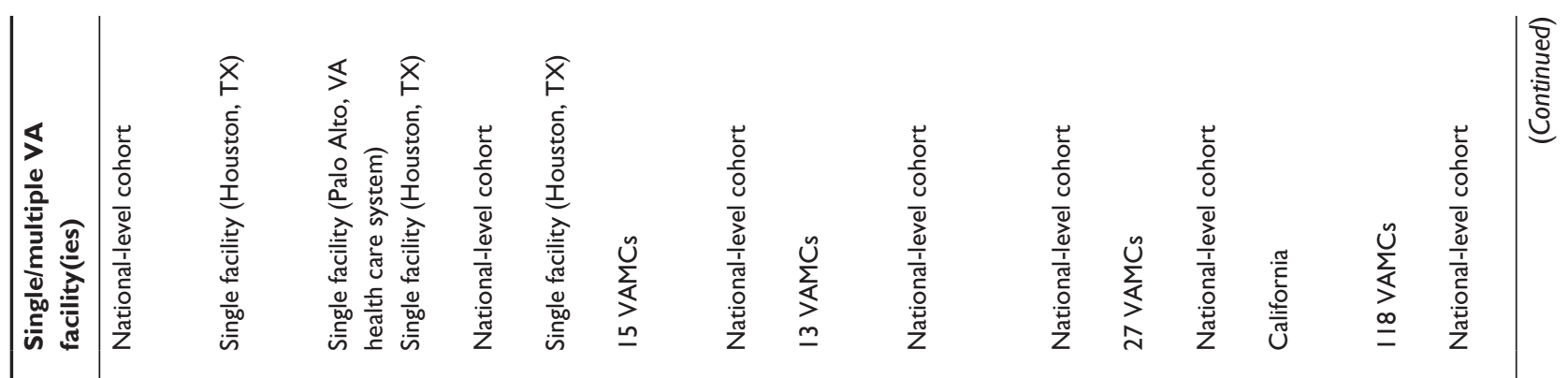

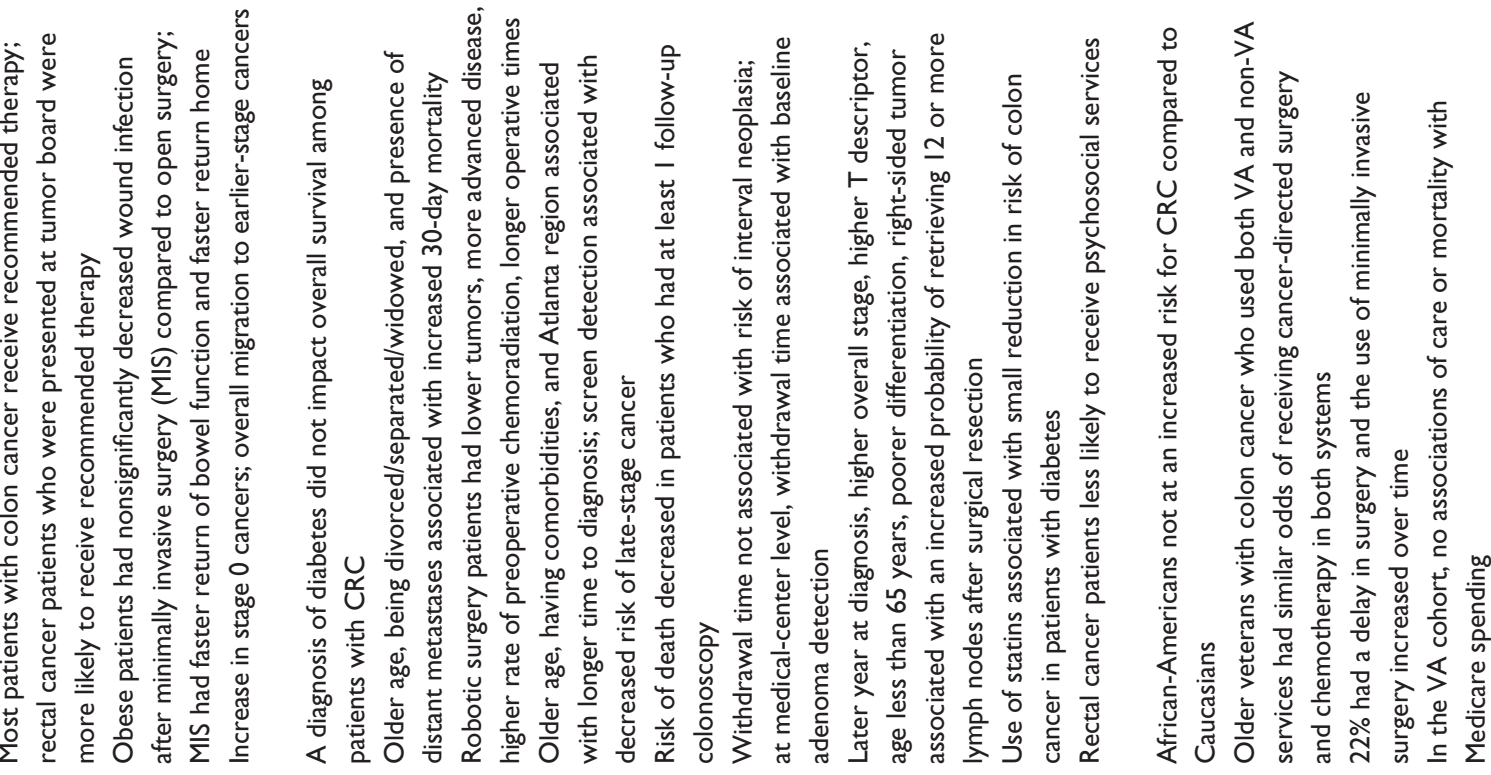
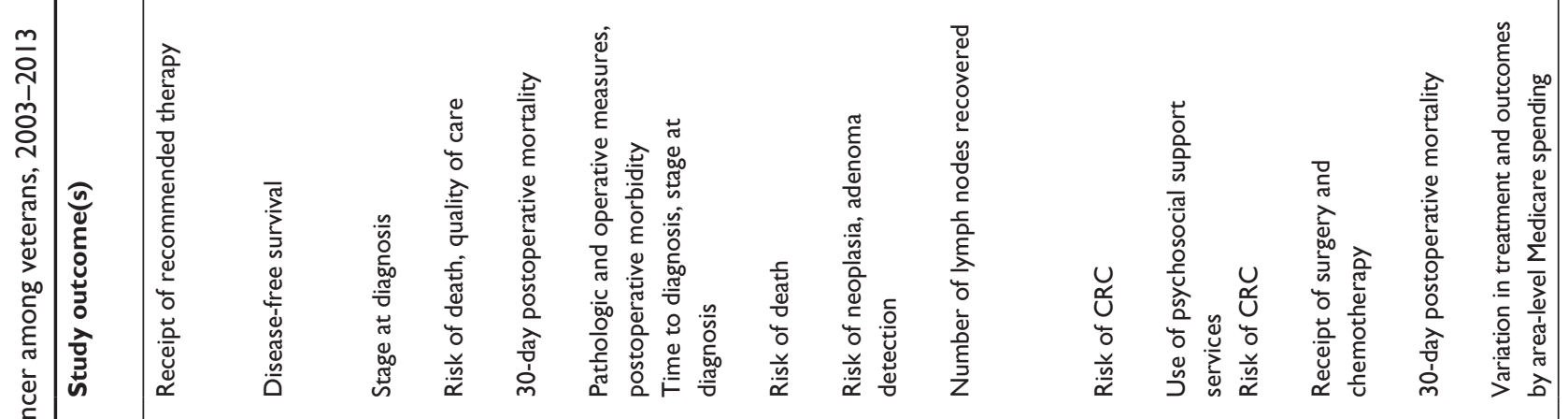

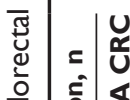

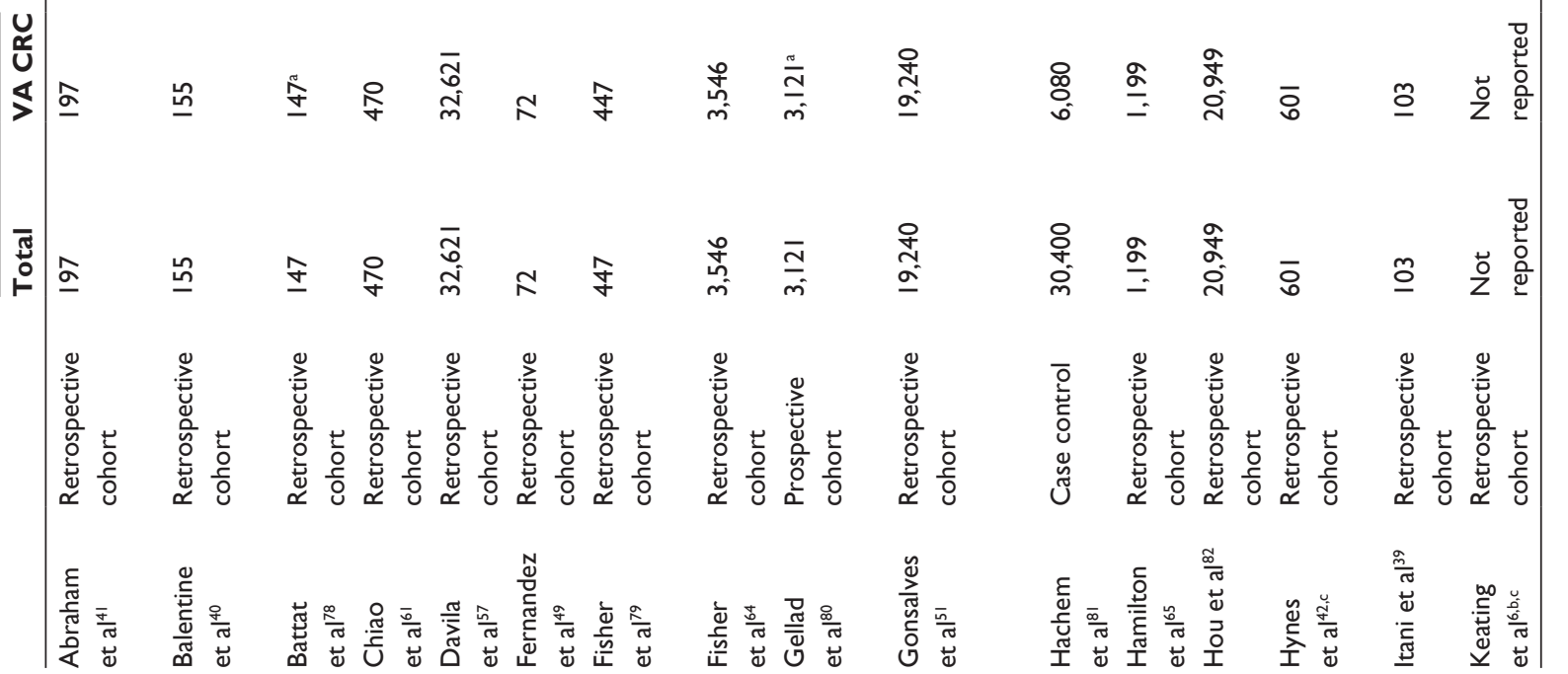




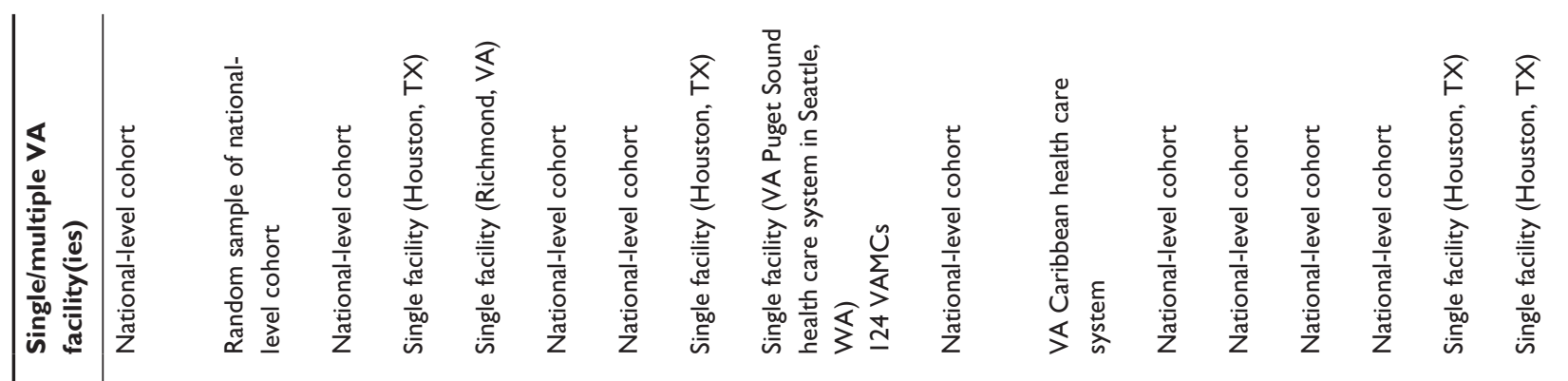

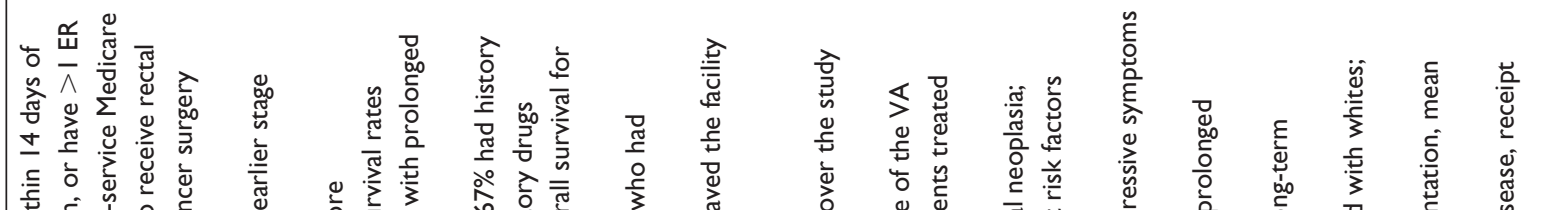

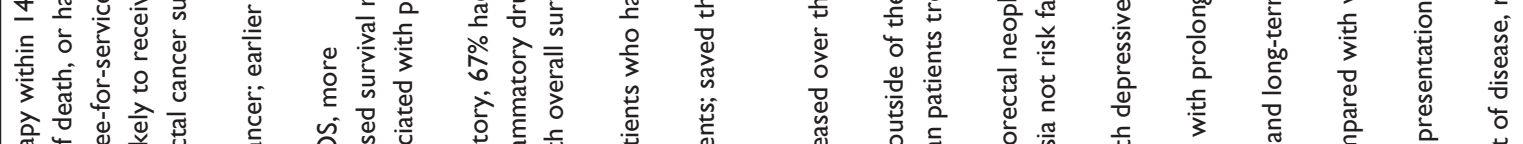

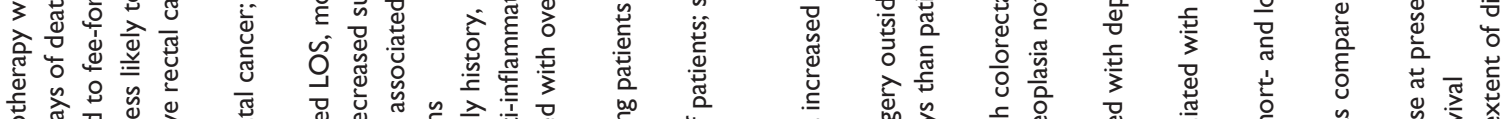

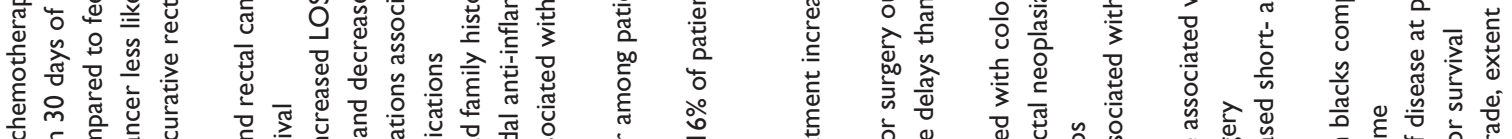

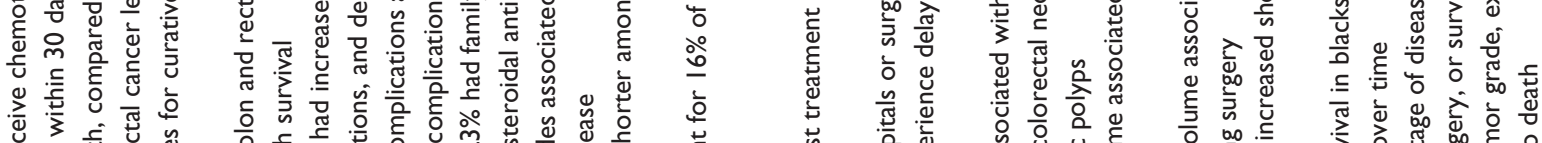

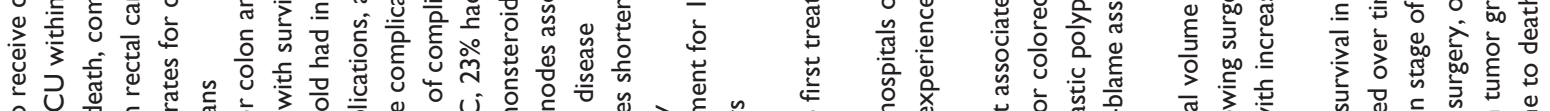

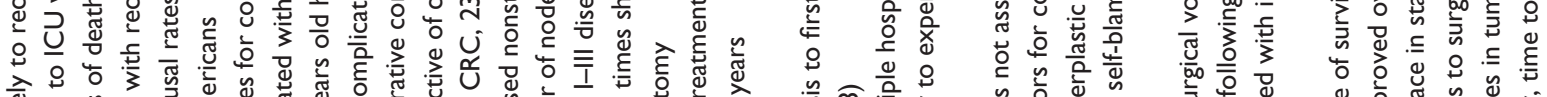

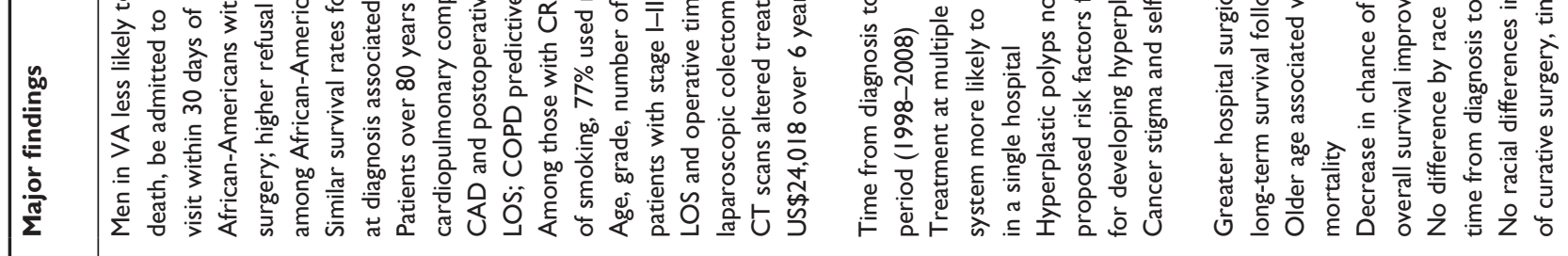

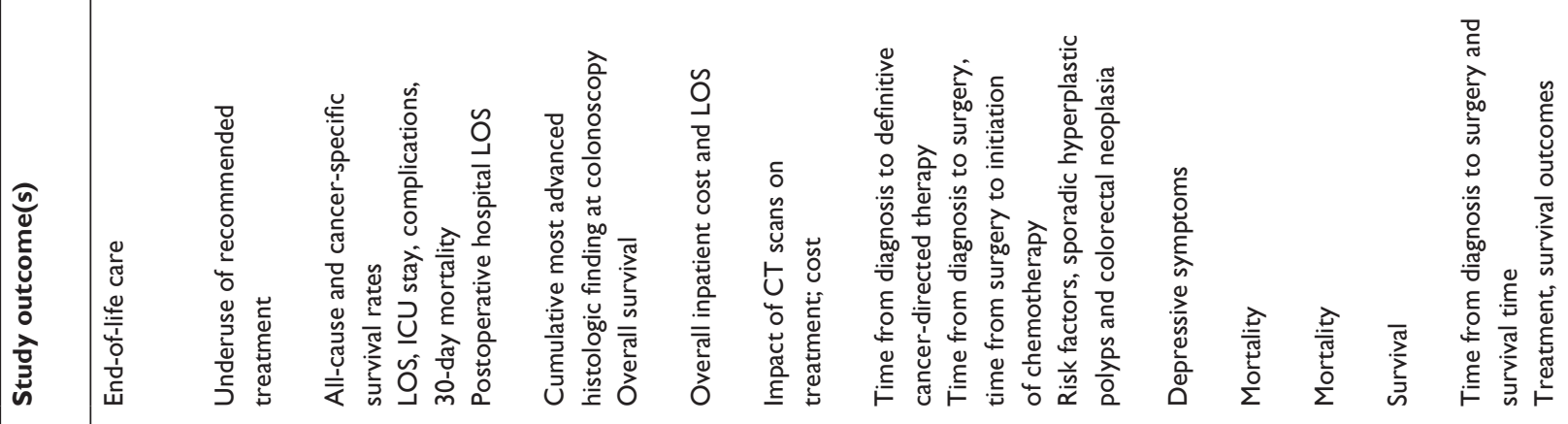

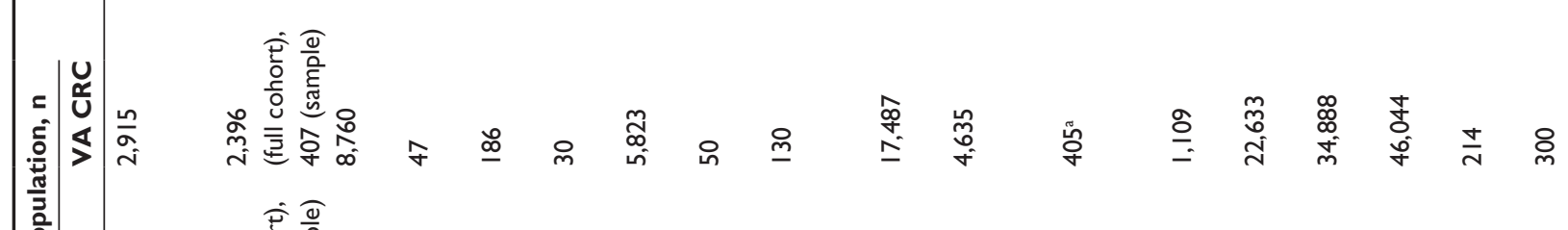

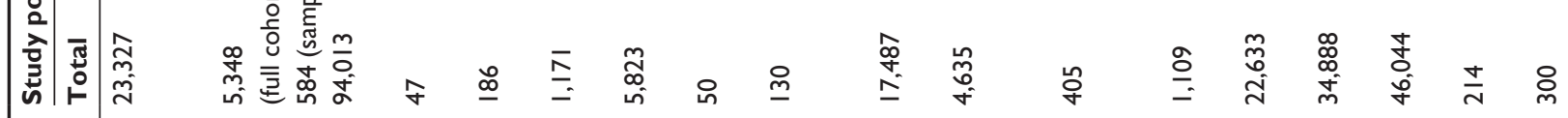

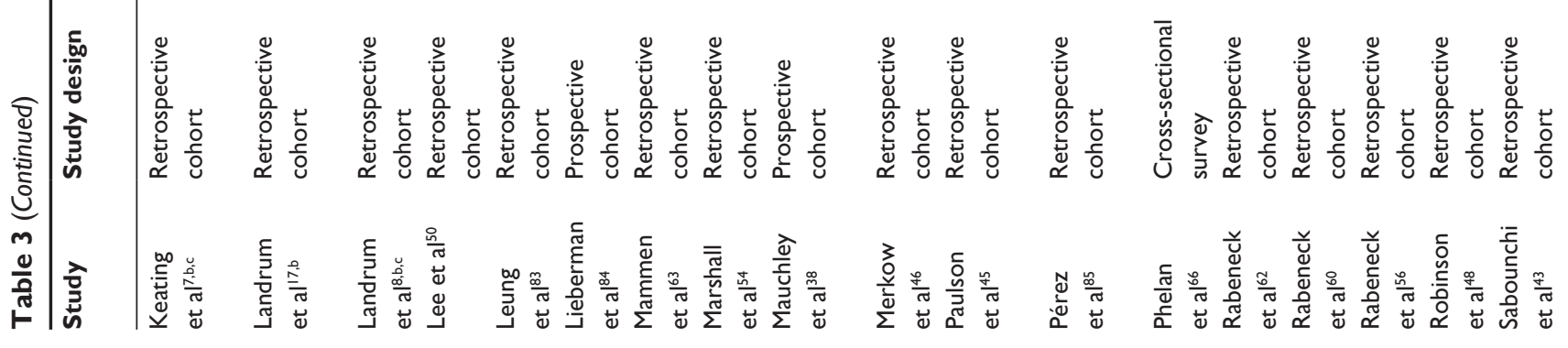




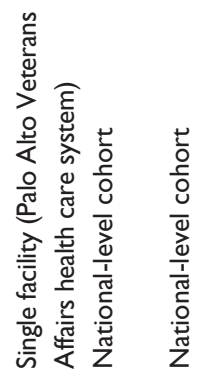

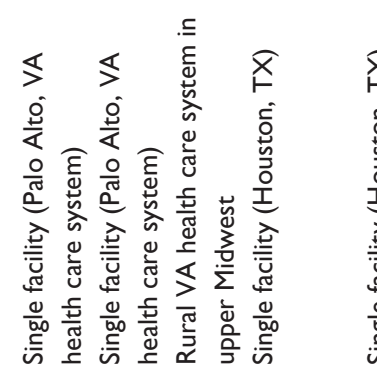

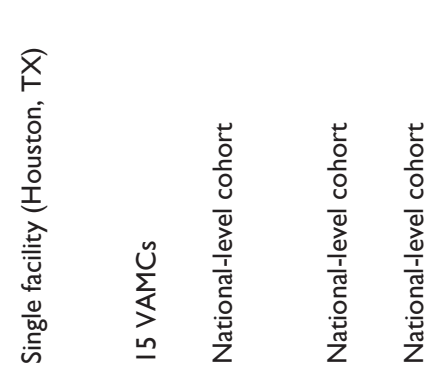

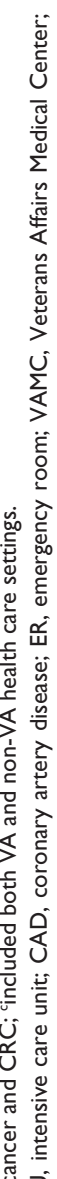

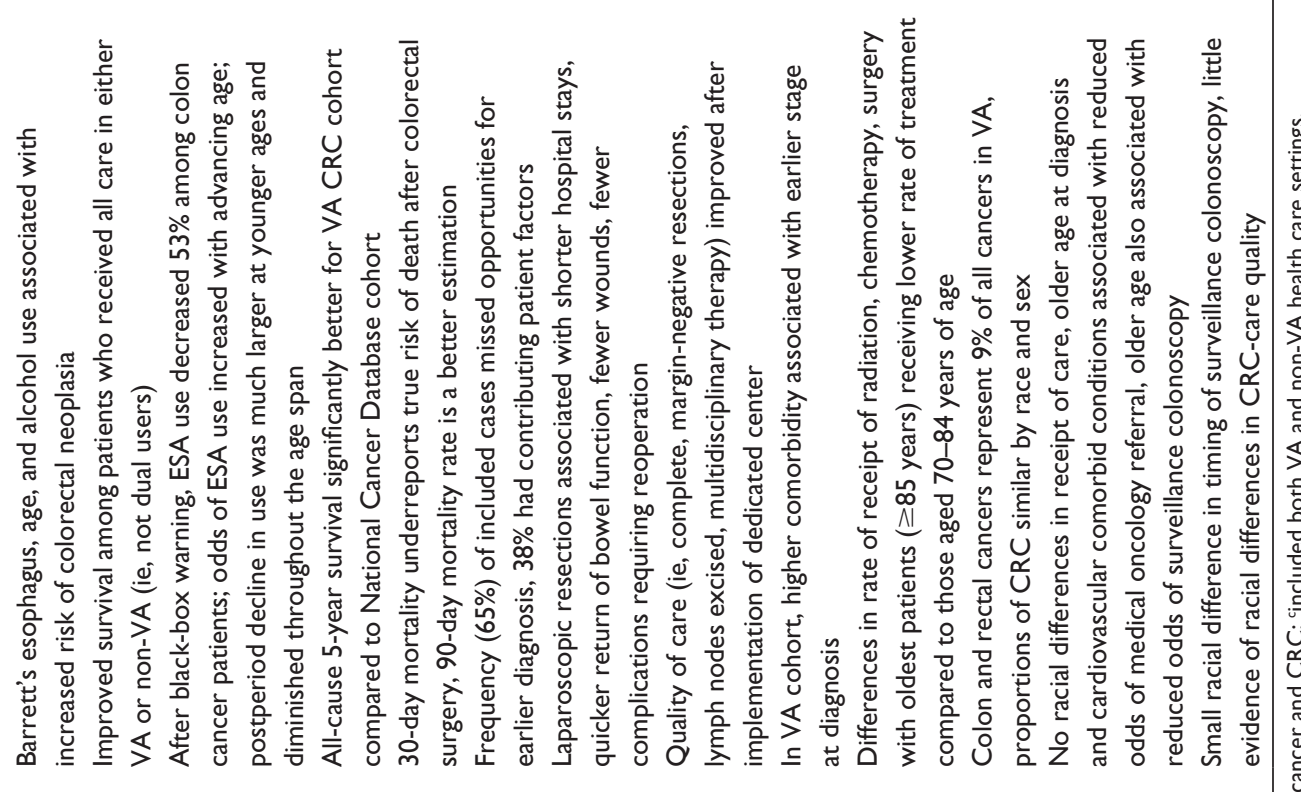

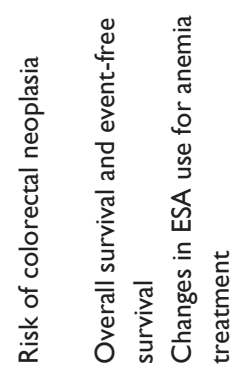

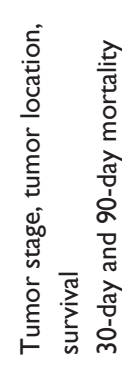

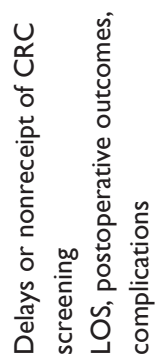

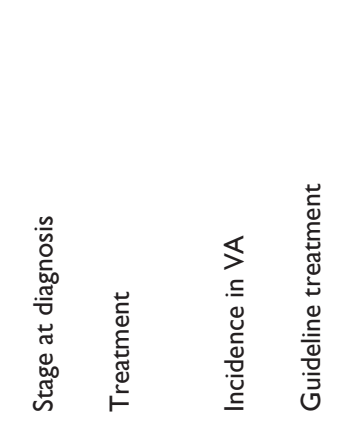

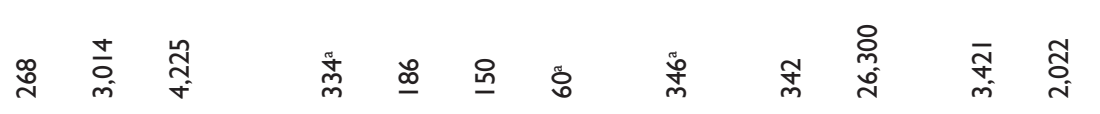

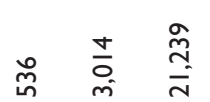

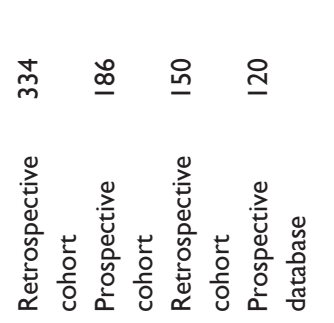

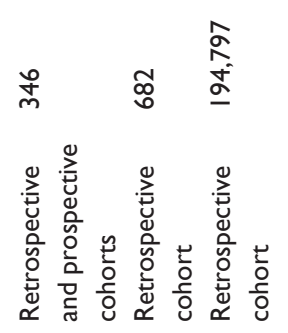

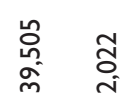

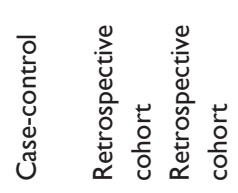

ब्य

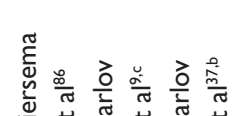

M

ชิ

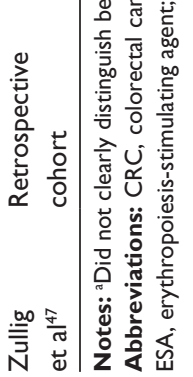




\section{Survival outcomes}

In a study by Dransfield et al, overall survival rate at 3 years was $65 \%$ among surgical patients, $80 \%$ among stage IA surgical patients in particular, and 30\% in nonsurgical patients. ${ }^{15}$ Another single-facility study of 178 resection patients reported that $102(57 \%)$ patients died during the study period, of whom $60 \%$ died from disease-specific causes, $18 \%$ from other causes, and 25\% from unknown causes. ${ }^{31}$ As it relates to short-term outcomes, one study found 30-day and 90 -day mortality rates to be $3.8 \%$ and $6.4 \%$, respectively, among pathologic stage IA resection patients. ${ }^{28}$

In studies evaluating predictors of survival, factors associated with worse survival included an increasing number of postoperative events ${ }^{28}$ and shorter times to treatment. ${ }^{21}$ While the correlation between shorter time to treatment and worse survival outcomes may be due to a myriad of factors, it is possible that this can also be attributed to patients with more advanced disease. One VA-wide study of patients with late-stage NSCLC found that African-Americans had longer overall survival (133 days) than whites (117) ${ }^{24}$ Three of the eight studies evaluating survival in veterans with LC were done at the state or national level, and compared survival among VA versus non-VA patients. Campling et al identified new LC patients diagnosed in 1995-1999 from the Pennsylvania Cancer Registry $(n=28,798)$ to compare patient characteristics and survival among VA and civilian patients. ${ }^{32} \mathrm{VA}$ patients had worse overall survival, based on 5-year survival rate of $12 \%$ among VA patients and $15 \%$ among non-VA patients. When examined by race, this significant survival difference among VA and non-VA patients was observed in white patients but not blacks. A similar comparative analysis was conducted among patients in Washington state diagnosed with LC between 2000 and 2006 identified by the VA and Surveillance, Epidemiology, and End Results (SEER) cancer registries. ${ }^{20}$ Veterans had worse survival within each stage compared to non-VA patients, but better overall survival when stages were combined, because VA had a significantly greater percentage of early-stage diagnoses.

Only one national-level study was done, and showed that VA patients had improved overall and cause-specific survival rates for NSCLC compared to SEER Medicare patients (hazard ratio [HR] $0.91,95 \%$ CI $0.88-0.95$ ), primarily due to more early stage patients in the VA population, because this survival benefit was no longer evident in stage-adjusted analyses. ${ }^{8}$ There was no survival difference for small-cell lung cancer (SCLC) (HR 0.99, 95\% CI 0.93-1.05). Also, survival outcomes were similar for VA and non-VA patients undergoing similar LC treatment.

\section{Other outcomes}

Two studies assessed health care utilization among LC patients. Au et al examined health care utilization in the last 6 months of life in patients with LC versus COPD who received care in one of seven VA facilities. ${ }^{33}$ Compared to those with COPD, LC patients were less likely to see their primary care provider and admitted to the intensive care unit less often, but more LC patients received palliative medications. A VA facility in the Midwest evaluated use of primary care before and after LC diagnosis, and reported no significant change in the overall primary care-utilization rate for chronic conditions (eg, hypertension), but found a significant decrease for acute conditions (eg, lower respiratory infection). ${ }^{34} \mathrm{~A}$ small study among advanced LC patients found that $53.2 \%$ discontinued statin use prior to death, and this was most often those receiving chemotherapy or with a history of cerebrovascular disease. ${ }^{35}$

We identified one study each that assessed communication, cost, and symptom management in two postdiagnostic clinic contexts: postangiogram consultations and initial lung cancer visits. ${ }^{36}$ Postdiagnostic patient-provider communication was compared between 88 patients during their postangiogram consultation and 62 patients during their initial LC visit. ${ }^{36}$ This study noted a greater frequency of active participation for LC patients and more facilitative talk by physicians of LC patients. Keating et al conducted a retrospective study to evaluate variation in area-level Medicare spending for cancer care. ${ }^{6}$ They did not find NSCLC to be associated with area-level spending in VA; however, the results suggested that the effects of spending on mortality in VA may be different than in the private sector. One study evaluated treatment with erythropoiesis-stimulating agents (ESAs) for anemia among 17,014 LC patients. ${ }^{37}$ In 2007, the US Food and Drug Administration issued a black-box warning for ESAs, because under certain circumstances ESAs may increase the risk of death and cancer progression. The study found that patients receiving chemotherapy after March 2007 had $65 \%$-reduced odds of ESA treatment compared to those treated with chemotherapy before $2007 .{ }^{37}$

\section{Colorectal cancer}

\section{Surgical and presurgical treatment}

We identified four studies evaluating preparation for and/or receipt of surgery. Mauchley et al examined the clinical utility of routine preoperative computed tomography (CT) scans and their cost-effectiveness in the treatment of patients with colon cancer; CT scans provided information that was used in treatment planning ( $33 \%$ of patients), and sometimes altered the 
model of treatment ( $16 \%$ of patients) ${ }^{38}$ Routine preoperative CT scans were also cost-effective, saving the institution in excess of US\$24,000 over a 6-year period. ${ }^{38}$ A national-level study of VA medical centers (VAMCs) using National Surgical Quality Improvement Program (NSQIP) data examined causes of mortality in CRC surgery and the longitudinal uptake of both cancer- and noncancer-directed laparoscopy. ${ }^{39}$ Over a 3-year period, the percentage of laparoscopy, a minimally invasive surgery, gradually increased from $3.5 \%$ (2003) to $10.1 \%$ (2005). Balentine et al used a database at their facility to evaluate minimally invasive CRC surgery among obese patients over an 8-year span (2002-2009). ${ }^{40}$ Of these obese patients, $73 \%(n=113)$ underwent open surgery, and $27 \%(n=42)$ had minimally invasive surgery. Conversion from open to minimally invasive surgery occurred in $25 \%$ of cases. At the Houston VAMC, Abraham et al examined receipt of appropriate therapy according to the National Cancer Institute's Physician Data Query (ie, stage II colon cancer patients receive surgical resection, stage III both surgery and chemotherapy). ${ }^{41}$ They found that most ( $87 \%$ of stage II and $71 \%$ of stage III) colon cancer patients received the recommended therapy, while fewer than half (42.5\%) of rectal cancer patients did. Among patients with rectal cancer, those whose clinical case was discussed at tumor board were more likely to receive the recommended therapy. ${ }^{41}$

Hynes et al addressed issues of cancer-care coordination among dually eligible patients (ie, eligible for VA and Medicare coverage). ${ }^{42}$ Among veterans with CRC in California, 72\% were initially diagnosed and treated in nonVA facilities. ${ }^{42}$ The authors compared surgery and adjuvant chemotherapy use between older California-based veterans with cancer receiving care in the VA system, outside of the VA system, and in both VA and non-VA systems. The odds of receiving cancer-directed surgery and chemotherapy were similar in both systems. Also, in both care settings, among stage III patients older age was associated with lower odds of receiving adjuvant chemotherapy. ${ }^{42}$ Zeber et al conducted a national-level study of elderly veterans comparing receipt of treatment for CRC patients aged $70-84$ years $(n=23,494)$ to those 85 years and older $(n=2,806)$, and found that $5.8 \%$ of patients aged $70-84$ years had surgery compared to $3.4 \%$ of those over 85 years. ${ }^{19}$ When Landrum et al examined reasons for underuse of recommended treatment, African-American veterans were less likely to receive rectal surgery $(66.6 \%$ versus $80.7 \%, P=0.002$ ), and curative surgery refusal rates were higher for African-Americans with stages I-III rectal cancer compared to white patients $(14.6 \%$ versus $4.8 \%$, $P=0.001) .{ }^{17}$

\section{Nonsurgical treatment}

Keating et al compared area-level variations in Medicare spending, cancer care received, and outcomes between patients enrolled in fee-for-service Medicare and VA. ${ }^{6}$ In contrast to the fee-for-service Medicare cohort, in the VA system there was minimal variation in CRC treatment by spending. ${ }^{6}$ In a study by Landrum et al evaluating dual users, relative to users of one system (ie, either VA or non-VA), dual users with stage II and III were substantially less likely to receive chemotherapy. ${ }^{8}$

We identified two studies evaluating possible racial variation in the provision of nonsurgical VA CRC care and one study evaluating variation by age. In a single-facility study, Sabounchi et al found that use of chemotherapy was significantly higher in white than black veterans (49\% versus $25 \%, P<0.001)$; however, there was no difference in receipt of radiotherapy. ${ }^{43}$ In a national-level study, Zullig et al found no racial difference for receipt of guideline-concordant $\mathrm{CRC}$ care, including preoperative carcinoembryonic antigen testing and surveillance colonoscopy. ${ }^{44}$ However, the authors determined that VA patients who were older at diagnosis may have had reduced odds of referral to medical oncology and surveillance colonoscopy. ${ }^{44}$ Zeber et al examined treatment modalities using a cross-sectional study of patients aged 70 years and older. ${ }^{19}$ Among CRC patients aged $70-84$ years, $1.3 \%$ received radiation and $3.9 \%$ received chemotherapy. For patients 85 years and older, $1.0 \%$ got radiation, while $1.2 \%$ got chemotherapy.

\section{Timeliness of care}

We identified five studies addressing timeliness of VA CRC care. Paulson et al found that compared to colon cancer patients treated entirely within their home VAMC, patients who required referral to a different hospital (ie, outside of their home VAMC) for surgery experienced delays in surgical intervention. ${ }^{45}$ For patients referred outside VA, there was an average delay of nearly 2 weeks. Those who then returned to VA for chemotherapy were more likely to receive initial treatment more than 8 weeks after surgery. Patients who went to another hospital to receive chemotherapy experienced delays; the average adjusted time from surgery to chemotherapy for these patients compared to those treated entirely within the VA health care system was 11.4 days $(P=0.003) .{ }^{45}$ Similarly, Merkow et al examined time from CRC diagnosis to first-course therapy, and found that time to first treatment increased over the study period (1998-2008) for both colon and rectal cancers. ${ }^{46}$

We identified one national ${ }^{47}$ and one single-facility study $^{48}$ examining racial differences in CRC-care timeliness. 
Zullig et al evaluated racial differences in stage-specific timeliness measures, such as time from surgery to initiation of adjuvant chemotherapy and surgery to surveillance colonoscopy. Though there was a small (average 16 days) racial difference in time to surveillance colonoscopy, the authors concluded that there was little evidence of racial differences in CRC quality among VA health care-system users. ${ }^{47}$ The single-study facility observed no significant racial difference in mean times from diagnosis to surgery. ${ }^{48}$ Another VA-wide study observed a delay to perform surgeries, both cancer- and noncancerdirected surgeries, in 23 patients $(22 \%) .{ }^{39}$

\section{Postoperative outcomes}

A single-institution study reported that robotic rectal resection compared to laparoscopy was associated with longer operative times, but there was no difference in surgical outcomes, such as blood loss, conversion rates, postoperative morbidity, lymph nodes harvested, margin positivity, or specimen quality. ${ }^{49}$ A national-level study examined patient characteristics, with special emphasis on race, associated with clear surgical margins for nonmetastatic CRC resection, and determined that there were no racial differences in clear surgical margins. ${ }^{44}$ In a study by Lee et al among surgical patients, compared to patients under 80 years old who had also had CRC-directed surgery, those 80 years and older had an increased length of stay $(21.4 \pm 4.1$ days for study group versus $11.1 \pm 0.9$ days for control group, $P=0.02$ ) and more cardiopulmonary complications $(P=0.01)$, and $32 \%$ presented in an emergency situation, which resulted in significantly longer hospital stays and increased incidence of complications. ${ }^{50}$

We identified two studies, one local and one national, addressing lymph-node retrieval. At a national level, Gonsalves et al evaluated clinical, pathological, and patient factors associated with lymph-node retrieval. ${ }^{51}$ The authors identified patients with resected stage I-III colon cancer between 2005 and 2008. They found that the mean number of lymph nodes retrieved increased over time, and was associated with higher stage, higher tumor descriptor, age less than 65 years, poorer differentiation, and right-side tumors $(P<0.01$ for all of these factors $) .{ }^{51}$ Another study at the VAMC in Houston, TX reported an increased percentage of complete, margin-negative resections $(P<0.05)$ and number of lymph nodes removed during surgery $(P<0.01)$ after establishing a minimally invasive CRC program. ${ }^{52}$ Investigators also compared outcomes of patients undergoing minimally invasive laparoscopic resections to age-matched patients who underwent open resections. ${ }^{53}$ They determined that patients undergoing laparoscopic procedures experienced shorter hospital stays and quicker return of bowel function. ${ }^{53}$ In 2009, the median inpatient cost of laparoscopic colectomy was 33\% less than open colectomy $(\$ 6,000, P<0.01) .{ }^{54}$ The median length of stay in the hospital and operative time were also reduced by $31 \%$ (3.5 days, $P<0.05$ ) and 37\% (108 minutes, $P<0.01)$, respectively, among those undergoing laparoscopy. ${ }^{54}$ Compared to those undergoing open CRC surgery, obese patients undergoing minimally invasive surgery had a significantly faster return of bowel function and returned home a median of 2 days earlier $(P<0.01) .{ }^{40}$ In a retrospective analysis of patients undergoing resection from 2002 to 2007 , the median length of stay was 8 days. ${ }^{55}$ In this study, coronary artery disease and postoperative complications were predictive of prolonged length of stay; COPD was predictive of complications. ${ }^{55}$

\section{Survival outcomes}

We identified two studies that assessed temporal trends in CRC mortality. The first VA-wide analysis evaluated temporal trends in survival among CRC patients admitted to VA hospitals. ${ }^{56}$ Significant survival differences were seen over time (1987-1998, $P<0.01)$ with longer survival times for patients diagnosed in more recent periods of time. In an adjusted analysis, there was an $18 \%$ increase in survival over time, and a small but significant decrease in the chance of surviving, in blacks compared to whites (adjusted relative survival $0.96,95 \%$ CI $0.92-0.99) .{ }^{56}$ The second study examined temporal changes in 30-day postoperative mortality using NSQIP data. ${ }^{57}$ Thirty-day postoperative mortality declined from 4.7\% during $1987-1988$ to $3.9 \%$ during $1998-2000$. Patients who received surgical resection during 1992-1994, 1995-1997, and 1998-2000 had a 14\%, 14\%, and 27\% lower adjusted risk of 30-day mortality, respectively, compared with those resected in 1987-1988. ${ }^{57}$ In another study of all VAMCs, the 30-day postsurgery mortality rate was $5.9 \%$. Visser et al measured both 30- and 90-day mortality following colectomy at a single facility. ${ }^{58}$ In this study, laparoscopic operations comprised $24.2 \%$ and open operations comprised $75.8 \%$ of colorectal surgery; most $(60.8 \%)$ were surgeries performed for neoplasms. ${ }^{58}$ The actual 30-day mortality rates were $4.3 \%, 1.4 \%$, and $15.8 \%$ for all, elective, and emergency procedures, respectively. ${ }^{58}$ They compared these rates to calculated NSQIP rates. The observed and calculated rates were similar. The risk-adjusted observed-to-expected ratio for 30 -day mortality was $4.8 \%, 1.8 \%$, and $18.2 \%$, respectively. However, 90-day mortality increased substantially to $9.1 \%$, $4.1 \%$, and $28.9 \%$, respectively. ${ }^{58}$ 
Numerous studies examined patient, hospital, or provider factors associated with survival. van Roessel et al determined that compared to National Cancer Database benchmarks, their VA facility had a greater percentage of early-stage cancers and better all-cause 5-year survival (VA 0.72, National Cancer Database 0.47; $P<0.001) .{ }^{59}$ We identified five studies addressing the correlation between patient factors and survival risk for VA patients with CRC. Rabeneck and colleagues compared 30-day and 5-year mortality in elderly versus younger patients following CRC-directed surgical resection. In patients at least 65 years of age with rectal or colon cancer, after adjustment the 30-day mortality was 2.5 times greater and 5 -year mortality was 1.5 times greater than in younger patients..$^{60}$ Lee et al also assessed the impact of age on survival by evaluating outcomes of patients aged 80 years and older who underwent surgery for CRC between 1996 and 2006. Older patients also had decreased survival rates at 1,3 , and 5 years $\left(71 \%, 48 \%\right.$, and $31 \%$ respectively). ${ }^{50}$ After stratifying by stage, survival between diabetic and nondiabetic patients with CRC was not significantly different. ${ }^{61}$ Two single-facility studies ${ }^{43,48}$ and one national study ${ }^{47}$ noted no racial differences in survival.

Landrum et al compared the survival rates of older patients with cancer receiving care in the VA health care system and fee-for-service Medicare. ${ }^{8}$ When compared to similar fee-forservice Medicare patients, patients receiving VA care had higher survival rates for colon cancer (HR 0.87, 95\% CI 0.82-0.93) and similar survival rates for rectal cancer (HR 1.05, 95\% CI $0.95-1.16) .{ }^{8}$ One study compared 3-year overall and cancerfree survival among patients with nonmetastatic colon cancer between patients who received substantial proportions of their care in both VA- and non-VA systems (dual users) and those who obtained care predominantly in VA or a non-VA system. ${ }^{9}$ Patients with stage I disease who received care predominantly in either VA (HR $0.40,95 \%$ CI $0.28-0.56$ ) or a non-VA system (HR 0.54, 95\% CI: 0.38, 0.78) had reduced hazard of dying compared with dual users. This was true for all stages of disease. For event-free survival, stage II and III VA users, but not nonVA users, had improved event-free survival. ${ }^{9}$ Dual users also had fewer total provider visits for colon cancer. In a study by Keating on area-level variation, in VA there was no statistically significant association of care delivered or mortality based on the level of Medicare spending. ${ }^{6}$

Greater surgical volume at a facility is a predictor of survival following CRC surgery. ${ }^{62}$ Among newly diagnosed CRC patients who underwent surgical resection in the VA system in fiscal years 1991-2000, 5-year cumulative survival was $52.1 \%$ among patients who received surgery in high-volume surgical hospitals, ie, those performing $\geq 25$ procedures annually, compared to $48.1 \%$ in low-volume hospitals. ${ }^{62}$ In adjusted analyses, there was a $7 \%$ and $11 \%$ increase in 5 -year survival for patients with colon and rectal cancers, respectively, compared to patients undergoing surgical resection in high- versus low-volume hospitals. ${ }^{62}$ Among stage II patients, overall survival increased with the higher number of lymph nodes examined and overall survival was greater with an increased number of positive lymph nodes $(P<0.001) .{ }^{63}$ The ratio of examined-to-positive lymph nodes was a stronger predictor of survival, with a 5 -year overall survival of $27 \%$ for the highest quartile versus $44 \%$ for the lowest. ${ }^{63}$

Fisher et a $l^{64}$ compared the mortality rates of patients who received at least one colonoscopy after their diagnosis with patients who had no further procedures. The adjusted risk of death at any point during 5 years of follow-up was decreased by $43 \%$ (HR $0.57,95 \%$ CI $0.51-0.63$ ) in the group who had a surveillance colonoscopy versus those who did not. ${ }^{64}$ The absolute difference in 5 -year mortality rate was approximately $12 \% .{ }^{64}$

\section{Other outcomes}

We identified few studies ( $\mathrm{n}=3$ ) addressing symptom management and psychosocial outcomes. In a national retrospective analysis examining ESA use for anemia management among colon cancer patients receiving chemotherapy, the odds of receiving ESA treatment decreased by 53\% (OR 0.47, 95\% CI 0.36-0.63) after the US Food and Drug Administration warning in 2007 compared to those treated before the warning. ${ }^{37}$

Two articles focused on psychosocial aspects of health and/or palliative care. The majority (78.6\%) of VA CRC patients obtain psychosocial services ${ }^{65}$ The most commonly accessed type of psychosocial service was chaplain services $(58.9 \%)$, followed by social work $(50.5 \%)$, psychiatry (7.1\%), psychology (6.2\%), mental health nurses $(3.5 \%)$, or another type of service (4.4\%) ${ }^{65}$ Phelan et al reported results from a self-administered survey to assess stigma, perceived blame, self-blame, and depressive symptoms in men with $\mathrm{CRC}$, and indicated that $31 \%$ of survey respondents agreed with at least one item in a measure of cancer stigma, and 25\% reported feeling at least a little to blame for their illness. ${ }^{66}$ Feelings of cancer stigma and self-blame were independent predictors of depressive symptoms. ${ }^{66}$

\section{Lung and colorectal cancer}

In a study including patients with metastatic LC or CRC, but not distinguishing between the two, Keating et al found 
that compared with fee-for-service Medicare, patients with metastatic cancer in the VA health care system appropriately received less aggressive end-of-life care. ${ }^{7}$ In particular, among matched cohorts, men in VA were less likely to receive chemotherapy within 14 days of death, be admitted to the intensive care unit within 30 days of death, or have more than one emergency room visit within 30 days of their death. ${ }^{7}$ This suggests that patients in VA may be receiving appropriate palliative care.

\section{Discussion}

The VA health care system is the largest integrated system in the US, and one of the largest providers of cancer care. ${ }^{5}$ Moreover, VA fulfills an important role by serving a unique patient population. VA patients often enter the health care system with a greater comorbidity burden, lower education and income, and lower health literacy. ${ }^{11-14}$ This literature review described treatment-utilization rates, factors associated with receipt of treatment, and outcomes for $\mathrm{LC}$ and $\mathrm{CRC}$ within the VA health care system.

\section{Summary of VA LC care}

Evidence from the reviewed studies on LC shows that resection rates were $65 \%-70 \%$, and closer to $50 \%$ among elderly populations. Among demographic factors, besides age, black race was also associated with lower resection rates, which has been widely reported for decades ${ }^{67}$ Clinical predictors of nonreceipt of surgery included such conditions as COPD and poor pulmonary function, as expected, since these are related to lung disease, and severe comorbidity. Together, these findings stress the need to identify ways to reduce variation in treatment by population subgroups, understand determinants of patient decisions regarding treatment, and identify any unmet patient needs or concerns that could improve resection rates. A significant portion of patients did not get recommended treatment for advanced disease; however, studies were few and confined to elderly populations. Studies assessing timeliness of care generally noted shorter times to care for advanced stages. Although some delay in lung cancer treatment is inevitable, due to the complexity of disease, large studies should attempt to identify and reduce any avoidable delay and assess the impact of delay on long-term outcomes. Numerous studies addressed survival outcomes among LC patients, but very few examined other patient outcomes (eg, quality of life, follow-up care, recurrence), and most studies were small. This is certainly an area for much-needed research to understand the impact of lung cancer care on both patient-reported and other clinical outcomes.

\section{Summary of VA CRC care}

Earlier stage at presentation was not associated with race, but was associated with improved long-term survival. In general, CRC patients receiving care in VA received appropriate cancer treatment ${ }^{44,68,69}$ and palliative care. ${ }^{7}$ Outcomes for older patients may be worse than younger patients and/or those with fewer comorbid conditions; while older patients may be less likely to receive certain types of treatment, such as chemotherapy, care is provided to older VA CRC patients at a similar rate as in the private sector. Overall, racial variation in VA CRC care is not evident, although there is room for improvement in a few areas, such as racially equal uptake of chemotherapy. The survival rates of older men with rectal and colon cancer are equal to and better than, respectively, the survival rates of men receiving care in fee-for-service Medicare.

\section{Summary of VA and non-VA comparisons}

Studies comparing VA and non-VA health care settings found mixed results with respect to quality of care and survival between patients treated within and outside VA. In terms of cancer-care quality, several studies indicated that quality indicators, such as length of stay after LC surgery ${ }^{30}$ and time to LC treatment, ${ }^{25}$ were better in settings outside VA. In contrast, other studies also reported improved quality within VA compared to non-VA settings. For example, studies found that VA LC patients were diagnosed at earlier stages, ${ }^{8,20}$ and both LC and CRC patients received less aggressive end-oflife care. ${ }^{7}$ Additionally, compared to CRC patients seeking care in the private sector, those with higher comorbidity burden were diagnosed at an early stage. ${ }^{10}$ There were also conflicting findings in terms of survival benefit between patients treated in VA and non-VA systems. For example, one study $^{32}$ found that VA LC patients had worse overall survival than non-VA patients; however, two other studies found that VA LC patients had better all-cause ${ }^{8,20}$ and cancer-specific survival. ${ }^{8}$ Better overall survival was also found among VA CRC patients. ${ }^{59}$ Findings were consistent regarding the perils of receiving care in dual systems: receiving care in one system, whether VA or non-VA, leads to better wait times and survival compared to using multiple systems..$^{9,45}$

\section{Limitations}

This review has several limitations. First, we synthesized the literature describing treatment and outcomes of care provided in the VA health care system. Care provided to veterans outside VA, either in nonfederal systems or through dual use of multiple systems, was not captured in this review. The extent of veterans receiving cancer care outside VA is 
not known. Secondly, these studies were dissimilar in many ways; lack of congruence in study design and content makes comparisons between VA and non-VA settings, as well as across VA settings, challenging. The included studies varied widely in terms of study population (eg, one center versus nationwide), study time frames, comparison groups (eg, another integrated health care system versus national database), and sample size. Because of heterogeneity in research design, there are limitations in the extent to which conclusions can be synthesized across studies.

\section{Future directions}

Mirroring that of those in military service, the composition of the VA population is changing. The VA serves an increasingly younger population with more female patients. ${ }^{70}$ As a result of this population shift, cancer-related treatment needs may also evolve. The VA cancer population approximately parallels that of US men; ${ }^{5}$ however, as more women receive care in VA, it is possible that VA may see an increase in cancers that are common among women. More research is needed to understand how and/or if VA should modify its cancer planning and services.

Relatively few studies included patient-reported outcomes and care experiences. Patient-reported information could lend additional insight into experiences of symptoms, functioning, health status, and quality of life. Understanding the patient perspective may provide critical insight into psychosocial needs, an underevaluated aspect of VA cancer treatment. Though these are important issues, future studies must extend beyond physical aspects of care and comprehensively assess patients' cancer care, including psychosocial, spiritual, mental, and palliative care needs.

\section{Acknowledgments and disclaimer}

This review was supported by the Department of Veterans Affairs, Veterans Health Administration, and Health Services Research and Development Service. LLZ was supported by a VA Health Services Research and Development (HSR\&D) Career Development Award (CDA 13-025). The views expressed in this article are those of the authors and do not necessarily represent the views of the Department of Veterans Affairs.

\section{Disclosure}

The authors report no conflicts of interest in this work.

\section{References}

1. Siegel R, Ma J, Zou Z, Jemal A. Cancer statistics, 2014. CA Cancer J Clin. 2014;64(1):9-29.
2. de Groot P, Munden RF. Lung cancer epidemiology, risk factors, and prevention. Radiol Clin North Am. 2012;50(5):863-876.

3. Johns LE, Houlston RS. A systematic review and meta-analysis of familial colorectal cancer risk. Am J Gastroenterol. 2001;96(10):2992-3003.

4. Wu AH, Paganini-Hill A, Ross RK, Henderson BE. Alcohol, physical activity and other risk factors for colorectal cancer: a prospective study. Br J Cancer. 1987;55(6):687-694.

5. Zullig LL, Jackson GL, Dorn RA, et al. Cancer incidence among patients of the US Veterans Affairs Health Care System. Mil Med. 2012;177(6): 693-701.

6. Keating NL, Landrum MB, Lamont EB, Bozeman SR, McNeil BJ. Arealevel variations in cancer care and outcomes. Med Care. 2012;50(5): 366-373.

7. Keating NL, Landrum MB, Lamont EB, Earle CC, Bozeman SR, McNeil BJ. End-of-life care for older cancer patients in the Veterans Health Administration versus the private sector. Cancer. 2010;116(15): 3732-3739.

8. Landrum MB, Keating NL, Lamont EB, et al. Survival of older patients with cancer in the Veterans Health Administration versus fee-for-service Medicare. J Clin Oncol. 2012;30(10):1072-1079.

9. Tarlov E, Lee TA, Weichle TW, et al. Reduced overall and event-free survival among colon cancer patients using dual system care. Cancer Epidemiol Biomarkers Prev. 2012;21(12):2231-2241.

10. Zafar SY, Abernethy AP, Abbott DH, et al. Comorbidity, age, race and stage at diagnosis in colorectal cancer: a retrospective, parallel analysis of two health systems. BMC Cancer. 2008;8:345.

11. Agha Z, Lofgren RP, VanRuiswyk JV, Layde PM. Are patients at Veterans Affairs medical centers sicker? A comparative analysis of health status and medical resource use. Arch Intern Med. 2000;160(21):3252-3257.

12. Kazis LE, Miller DR, Clark J, et al. Health-related quality of life in patients served by the Department of Veterans Affairs: results from the Veterans Health Study. Arch Intern Med. 1998;158(6):626-632.

13. Kazis LE, Miller DR, Skinner KM, et al. Patient-reported measures of health: the Veterans Health Study. J Ambul Care Manage. 2004;27(1): $70-83$.

14. Liu CF, Maciejewski ML, Sales AE. Changes in characteristics of veterans using the VHA health care system between 1996 and 1999. Health Res Policy Syst. 2005;3(1):5.

15. Dransfield MT, Lock BJ, Garver RI Jr. Improving the lung cancer resection rate in the US Department of Veterans Affairs Health System. Clin Lung Cancer. 2006;7(4):268-272.

16. Williams CD, Stechuchak KM, Zullig LL, Provenzale D, Kelley MJ. Influence of comorbidity on racial differences in receipt of surgery among US veterans with early-stage non-small-cell lung cancer. J Clin Oncol. 2013;31(4):475-481.

17. Landrum MB, Keating NL, Lamont EB, Bozeman SR, McNeil BJ. Reasons for underuse of recommended therapies for colorectal and lung cancer in the Veterans Health Administration. Cancer. 2012;118(13): 3345-3355.

18. Wang S, Wong ML, Hamilton N, Davoren JB, Jahan TM, Walter LC. Impact of age and comorbidity on non-small-cell lung cancer treatment in older veterans. J Clin Oncol. 2012;30(13):1447-1455.

19. Zeber JE, Copeland LA, Hosek BJ, Karnad AB, Lawrence VA, SanchezReilly SE. Cancer rates, medical comorbidities, and treatment modalities in the oldest patients. Crit Rev Oncol Hematol. 2008;67(3):237-242.

20. Zeliadt SB, Sekaran NK, Hu EY, et al. Comparison of demographic characteristics, surgical resection patterns, and survival outcomes for veterans and nonveterans with non-small cell lung cancer in the Pacific Northwest. J Thorac Oncol. 2011;6(10):1726-1732.

21. Gould MK, Ghaus SJ, Olsson JK, Schultz EM. Timeliness of care in veterans with non-small cell lung cancer. Chest. 2008;133(5):1167-1173.

22. Powell AA, Schultz EM, Ordin DL, et al. Timeliness across the continuum of care in veterans with lung cancer. J Thorac Oncol. 2008; 3(9):951-957.

23. Schultz EM, Powell AA, McMillan A, et al. Hospital characteristics associated with timeliness of care in veterans with lung cancer. Am J Respir Crit Care Med. 2009;179(7):595-600. 
24. Zullig LL, Carpenter WR, Provenzale DT, et al. The association of race with timeliness of care and survival among Veterans Affairs health care system patients with late-stage non-small cell lung cancer. Cancer Manag Res. 2013;5:157-163.

25. Wang L, Correa CR, Hayman JA, et al. Time to treatment in patients with stage III non-small cell lung cancer. Int J Radiat Oncol Biol Phys. 2009;74(3):790-795.

26. Hunnibell LS, Rose MG, Connery DM, et al. Using nurse navigation to improve timeliness of lung cancer care at a veterans hospital. Clin J Oncol Nurs. 2012;16(1):29-36.

27. Riedel RF, Wang X, McCormack M, et al. Impact of a multidisciplinary thoracic oncology clinic on the timeliness of care. J Thorac Oncol. 2006;1(7):692-696.

28. St Julien JB, Pinkerman R, Aldrich MC, et al. Poor survival for veterans with pathologic stage I non-small-cell lung cancer. Am J Surg. 2012;204(5):637-642.

29. Cajipe MD, Chu D, Bakaeen FG, et al. Video-assisted thoracoscopic lobectomy is associated with better perioperative outcomes than open lobectomy in a veteran population. Am J Surg. 2012;204(5):607-612.

30. DeArmond DT, Simmons JD, Cline AM, Zarzabal LA, Johnson SB, Baisden CE. Feasibility of video-assisted thoracoscopic surgery lobectomy in Veterans Administration patients. Am J Surg. 2012;204(5): e15-e20.

31. Reed MF, Molloy M, Dalton EL, Howington JA. Survival after resection for lung cancer is the outcome that matters. Am J Surg. 2004;188(5): 598-602.

32. Campling BG, Hwang WT, Zhang J, et al. A population-based study of lung carcinoma in Pennsylvania: comparison of Veterans Administration and civilian populations. Cancer. 2005;104(4):833-840.

33. Au DH, Udris EM, Fihn SD, McDonell MB, Curtis JR. Differences in health care utilization at the end of life among patients with chronic obstructive pulmonary disease and patients with lung cancer. Arch Intern Med. 2006;166(3):326-331.

34. Jones LE, Carney Doebbeling C. Primary care utilization patterns before and after lung cancer diagnosis. Eur J Cancer Care (Engl). 2009;18(2): $165-173$.

35. Tanvetyanon T, Choudhury AM. Physician practice in the discontinuation of statins among patients with advanced lung cancer. J Palliat Care. 2006;22(4):281-285.

36. Street RL Jr, Gordon HS. The clinical context and patient participation in post-diagnostic consultations. Patient Educ Couns. 2006;64(1-3): 217-224.

37. Tarlov E, Stroupe KT, Lee TA, et al. Trends in anemia management in lung and colon cancer patients in the US Department of Veterans Affairs, 2002-2008. Support Care Cancer. 2012;20(8):1649-1657.

38. Mauchley DC, Lynge DC, Langdale LA, Stelzner MG, Mock CN, Billingsley KG. Clinical utility and cost-effectiveness of routine preoperative computed tomography scanning in patients with colon cancer. Am J Surg. 2005;189(5):512-517; discussion 517.

39. Itani KM, Denwood R, Schifftner T, et al. Causes of high mortality in colorectal surgery: a review of episodes of care in Veterans Affairs hospitals. Am J Surg. 2007;194(5):639-645.

40. Balentine CJ, Marshall C, Robinson C, et al. Obese patients benefit from minimally invasive colorectal cancer surgery. J Surg Res. 2010;163(1): 29-34.

41. Abraham NS, Gossey JT, Davila JA, Al-Oudat S, Kramer JK. Receipt of recommended therapy by patients with advanced colorectal cancer. Am J Gastroenterol. 2006;101(6):1320-1328.

42. Hynes DM, Tarlov E, Durazo-Arvizu R, et al. Surgery and adjuvant chemotherapy use among veterans with colon cancer: insights from a California study. J Clin Oncol. 2010;28(15):2571-2576.

43. Sabounchi S, Keihanian S, Anand BS. Impact of race on colorectal cancer. Clin Colorectal Cancer. 2012;11(1):66-70.

44. Zullig LL, Carpenter WR, Provenzale D, Weinberger M, Reeve BB, Jackson GL. Examining potential colorectal cancer care disparities in the Veterans Affairs health care system. J Clin Oncol. 2013;31(28): 3579-3584.
45. Paulson EC, Fu X, Epstein AJ. Location and timing of care for colon cancer patients in the VA Health System. J Surg Res. 2013;183(2): 639-644.

46. Merkow RP, Bilimoria KY, Sherman KL, McCarter MD, Gordon HS, Bentrem DJ. Efficiency of colorectal cancer care among veterans: analysis of treatment wait times at Veterans Affairs Medical Centers. J Oncol Pract. 2013;9(4):e154-e163.

47. Zullig LL, Jackson GL, Weinberger M, Provenzale D, Reeve BB, Carpenter WR. An examination of racial differences in process and outcome of colorectal cancer care quality among users of the veterans affairs health care system. Clin Colorectal Cancer. 2013;12(4): 255-260.

48. Robinson CN, Balentine CJ, Marshall CL, et al. Ethnic disparities are reduced in VA colon cancer patients. Am J Surg. 2010;200(5): 636-639.

49. Fernandez R, Anaya DA, Li LT, et al. Laparoscopic versus robotic rectal resection for rectal cancer in a veteran population. Am J Surg. 2013;206(4):509-517.

50. Lee L, Jannapureddy M, Albo D, et al. Outcomes of Veterans Affairs patients older than age 80 after surgical procedures for colon malignancies. Am J Surg. 2007;194(5):646-651.

51. Gonsalves WI, Kanuri S, Tashi T, et al. Clinicopathologic factors associated with lymph node retrieval in resectable colon cancer: a Veterans' Affairs Central Cancer Registry (VACCR) database analysis. J Surg Oncol. 2011;104(6):667-671.

52. Wilks JA, Liebig C, Tasleem SH, et al. Rectal cancer patients benefit from implementation of a dedicated colorectal cancer center in a Veterans Affairs Medical Center. Am J Surg. 2009;198(1):100-104.

53. Wilks JA, Balentine CJ, Berger DH, et al. Establishment of a minimally invasive program at a Veterans'Affairs Medical Center leads to improved care in colorectal cancer patients. Am J Surg. 2009;198(5):685-692.

54. Marshall CL, Chen GJ, Robinson CN, et al. Establishment of a minimally invasive surgery program leads to decreased inpatient cost of care in veterans with colon cancer. Am J Surg. 2010;200(5):632-635.

55. Leung JW, Mann SK, Siao-Salera R, et al. A randomized, controlled comparison of warm water infusion in lieu of air insufflation versus air insufflation for aiding colonoscopy insertion in sedated patients undergoing colorectal cancer screening and surveillance. Gastrointest Endosc. 2009;70(3):505-510.

56. Rabeneck L, Souchek J, El-Serag HB. Survival of colorectal cancer patients hospitalized in the Veterans Affairs Health Care System. Am J Gastroenterol. 2003;98(5):1186-1192.

57. Davila JA, Rabeneck L, Berger DH, El-Serag HB. Postoperative 30-day mortality following surgical resection for colorectal cancer in veterans: changes in the right direction. Dig Dis Sci. 2005;50(9):1722-1728.

58. Visser BC, Keegan H, Martin M, Wren SM. Death after colectomy: it's later than we think. Arch Surg. 2009;144(11):1021-1027.

59. van Roessel P, Rouse RV, Wren SM. Care within a veterans hospital: earlier detection of colon cancer. Surg Endosc. 2007;21(8):1434-1440.

60. Rabeneck L, Davila JA, Thompson M, El-Serag HB. Outcomes in elderly patients following surgery for colorectal cancer in the Veterans Affairs health care system. Aliment Pharmacol Ther. 2004;20(10): 1115-1124.

61. Chiao EY, Nambi PV, Naik AD. The impact of diabetes process and outcome quality measures on overall survival in patients with co-morbid colorectal cancer. J Cancer Surviv. 2010;4(4):381-387.

62. Rabeneck L, Davila JA, Thompson M, El-Serag HB. Surgical volume and long-term survival following surgery for colorectal cancer in the Veterans Affairs Health-Care System. Am J Gastroenterol. 2004;99(4): 668-675.

63. Mammen JM, James LE, Molloy M, Williams A, Wray CJ, Sussman JJ. The relationship of lymph node dissection and colon cancer survival in the Veterans Affairs Central Cancer Registry. Am J Surg. 2007;194(3): 349-354.

64. Fisher DA, Jeffreys A, Grambow SC, Provenzale D. Mortality and follow-up colonoscopy after colorectal cancer. Am J Gastroenterol. 2003;98(4):901-906. 
65. Hamilton NS, Jackson GL, Abbott DH, Zullig LL, Provenzale D. Use of psychosocial support services among male Veterans Affairs colorectal cancer patients. J Psychosoc Oncol. 2011;29(3):242-253.

66. Phelan SM, Griffin JM, Jackson GL, et al. Stigma, perceived blame, self-blame, and depressive symptoms in men with colorectal cancer. Psychooncology. 2013;22(1):65-73.

67. Hardy D, Liu CC, Xia R, et al. Racial disparities and treatment trends in a large cohort of elderly black and white patients with nonsmall cell lung cancer. Cancer. 2009;115(10):2199-2211.

68. Jackson GL, Melton LD, Abbott DH, et al. Quality of nonmetastatic colorectal cancer care in the Department of Veterans Affairs. J Clin Oncol. 2010;28(19):3176-3181.

69. Jackson GL, Zullig LL, Zafar SY, et al. Using NCCN clinical practice guidelines in oncology to measure the quality of colorectal cancer care in the Veterans Health Administration. J Natl Compr Canc Netw. 2013;11(4):431-441.

70. Meehan S. Improving health care for women veterans. J Gen Intern Med. 2006;21(S3):S1-S2.

71. Capo-Ramos DE, Gao Y, Lubin JH, et al. Mood disorders and risk of lung cancer in the EAGLE case-control study and in the US Veterans Affairs inpatient cohort. PloS One. 2012;7(8):e42945.

72. Gould MK, Ananth L, Barnett PG. A clinical model to estimate the pretest probability of lung cancer in patients with solitary pulmonary nodules. Chest. 2007;131(2):383-388.

73. Khurana V, Bejjanki HR, Caldito G, Owens MW. Statins reduce the risk of lung cancer in humans: a large case-control study of US veterans. Chest. 2007;131(5):1282-1288.

74. Khurana R, Wolf R, Berney S, Caldito G, Hayat S, Berney SM. Risk of development of lung cancer is increased in patients with rheumatoid arthritis: a large case control study in US veterans. J Rheumatol. 2008;35(9):1704-1708.

75. Kouri EM, Landrum MB, Lamont EB, Bozeman S, McNeil BJ, Keating NL. Location of cancer surgery for older veterans with cancer. Health Serv Res. 2012;47(2):783-793.
76. Rao GA, Mann JR, Shoaibi A, et al. Angiotensin receptor blockers: are they related to lung cancer? J Hypertens. 2013;31(8):1669-1675.

77. Sigel K, Wisnivesky J, Gordon K, et al. HIV as an independent risk factor for incident lung cancer. AIDS. 2012;26(8):1017-1025.

78. Battat AC, Rouse RV, Dempsey L, Safadi BY, Wren SM. Institutional commitment to rectal cancer screening results in earlier-stage cancers on diagnosis. Ann Surg Oncol. 2004;11(11):970-976.

79. Fisher DA, Zullig LL, Grambow SC, et al. Determinants of medical system delay in the diagnosis of colorectal cancer within the Veteran Affairs Health System. Dig Dis Sci. 2010;55(5):1434-1441.

80. Gellad ZF, Weiss DG, Ahnen DJ, Lieberman DA, Jackson GL, Provenzale D. Colonoscopy withdrawal time and risk of neoplasia at 5 years: results from VA Cooperative Studies Program 380. Am J Gastroenterol. 2010;105(8):1746-1752.

81. Hachem C, Morgan R, Johnson M, Kuebeler M, El-Serag H. Statins and the risk of colorectal carcinoma: a nested case-control study in veterans with diabetes. Am J Gastroenterol. 2009;104(5):1241-1248.

82. Hou JK, Kramer JR, Richardson P, Mei M, El-Serag HB. Risk of colorectal cancer among Caucasian and African American veterans with ulcerative colitis. Inflamm Bowel Dis. 2012;18(6):1011-1017.

83. Leung AM, Gibbons RL, Vu HN. Predictors of length of stay following colorectal resection for neoplasms in 183 Veterans Affairs patients. World J Surg. 2009;33(10):2183-2188.

84. Lieberman DA, Weiss DG, Harford WV, et al. Five-year colon surveillance after screening colonoscopy. Gastroenterology. 2007;133(4): 1077-1085.

85. Pérez R, LasaA, Toro DH, Cruz-Correa M, Martinez-Souss J. Relationship between sporadic hyperplastic polyps and colorectal neoplasia in Hispanic veterans. P R Health Sci J. 2010;29(4):372-376.

86. Siersema PD, Yu S, Sahbaie P, et al. Colorectal neoplasia in veterans is associated with Barrett's esophagus but not with proton-pump inhibitor or aspirin/NSAID use. Gastrointest Endosc. 2006;63(4):581-586.

87. Wahls TL, Peleg I. Patient- and system-related barriers for the earlier diagnosis of colorectal cancer. BMC Fam Pract. 2009;10:65.
Cancer Management and Research

\section{Publish your work in this journal}

Cancer Management and Research is an international, peer-reviewed open access journal focusing on cancer research and the optimal use of preventative and integrated treatment interventions to achieve improved outcomes, enhanced survival and quality of life for the cancer patient The journal welcomes original research, clinical \& epidemiological

\section{Dovepress}

studies, reviews \& evaluations, guidelines, expert opinion \& commentary, case reports \& extended reports. The manuscript management system is completely online and includes a very quick and fair peerreview system, which is all easy to use. Visit http://www.dovepress.com/ testimonials.php to read real quotes from published authors. 